
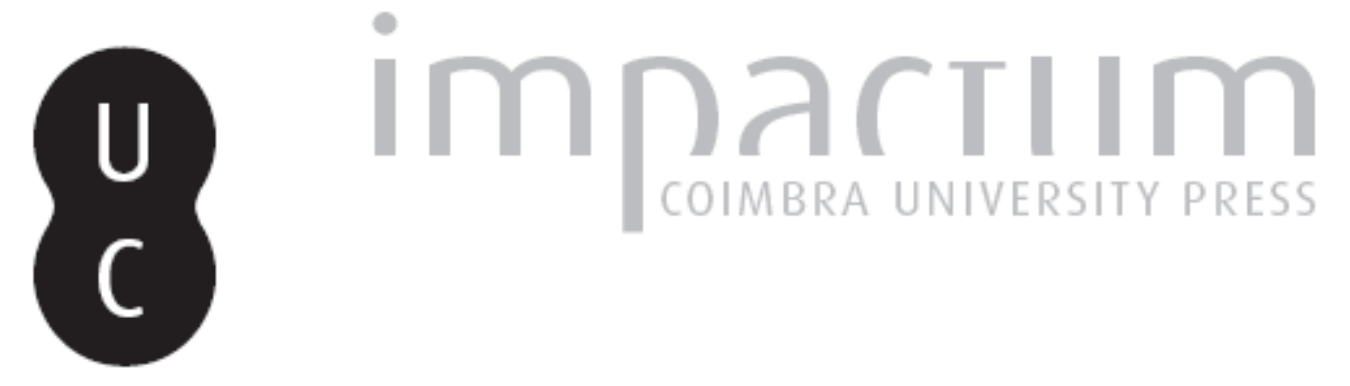

\title{
Determinação da fragilidade ambiental na bacia do Rio Verde, região Nordeste do estado de São Paulo, Brasil
}

Autor(es): $\quad$ Vitte, Antonio Carlos; Mello, Juliano Pereira de

Publicado por: Associação Portuguesa de Riscos, Prevenção e Segurança

URL persistente:

URI:http://hdl.handle.net/10316.2/36151

DOI:

DOI:http://dx.doi.org/10.14195/1647-7723_16_8

Accessed : $\quad$ 26-Apr-2023 12:22:58

A navegação consulta e descarregamento dos títulos inseridos nas Bibliotecas Digitais UC Digitalis, UC Pombalina e UC Impactum, pressupõem a aceitação plena e sem reservas dos Termos e Condições de Uso destas Bibliotecas Digitais, disponíveis em https://digitalis.uc.pt/pt-pt/termos.

Conforme exposto nos referidos Termos e Condições de Uso, o descarregamento de títulos de acesso restrito requer uma licença válida de autorização devendo o utilizador aceder ao(s) documento(s) a partir de um endereço de IP da instituição detentora da supramencionada licença.

Ao utilizador é apenas permitido o descarregamento para uso pessoal, pelo que o emprego do(s) título(s) descarregado(s) para outro fim, designadamente comercial, carece de autorização do respetivo autor ou editor da obra.

Na medida em que todas as obras da UC Digitalis se encontram protegidas pelo Código do Direito de Autor e Direitos Conexos e demais legislação aplicável, toda a cópia, parcial ou total, deste documento, nos casos em que é legalmente admitida, deverá conter ou fazer-se acompanhar por este aviso.

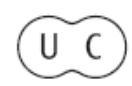




\section{territorium}

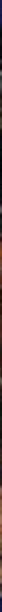

16

Revista da Associação Portuguesa de Riscos, Prevenção e Segurança 2009 


\title{
DETERMINAÇÃO DA FRAGILIDADE AMBIENTAL NA BACIA DO RIO VERDE, REGIÃO NORDESTE DO ESTADO DE SÃO PAULO, BRASIL
}

\author{
Antonio Carlos Vitte \\ Professor do Departamento de Geografia da Unicamp, Campinas (SP) , Brasil. Pesquisador ANPq \\ vittearal.com.br
}

Juliano Pereira de Mello

Professor de Geografia da Rede Pública e Particular do Estado de São Paulo. Nestre em Geografia pela Unicamp

juliano.melloahotmail.com

\section{RESUMO}

Este trabalho apresenta um ensaio cartográfico para a determinação da fragili idade ambiental na Bacia Hidrográfica do Rio Verde (SP) , localizada numa área de contato entre as rochas cristalinas da Serra da Mentiqueira e os terrenos sedimentares da Depressão Periférica Paulista.

Analisamos as características histórico-social-econômicas da Bacia, a qual é marcada pelas práticas agropecuárias, principalmente, as ligadas aos plantios de cana-de-açúcar, batata e cebola, além da criação de gado bovino. Mapeamos e analisamos os dados sobre geologia, pedologia, drenagem, hipsometria, declividades e de uso e ocupação das terras, os quais, foram tratados em ambiente SIG e integrados por um algoritmo para chegarmos a um mapa síntese das classes de fragilidade ambiental na Bacia.

Concluímos que a maior parte da área formada pela junção das classes de média a muito alta fragilidade estão na porção da bacia hidrográfica que corresponde aos domínios da Serra da Mantiqueira - maior intensidade dos processos de morfogênese.

Palavras chave: Bacia hidrográfica; fragilidade ambiental; Geomorfologia, metodblogia, Brasil.

\section{RÉSUMÉ}

Cet article présente un essai cartographique pour la détermination de la fragilitíé environnementale du Bassin Hychrographique de Rio Verde (SP) , localisé dans une aire de contact entre les roches cristallines de la Serra da Mentiqueira et les terrains sédimentaires de la Dépression Périphérique Pauliste.

on analyse les caractéristiques historiques, sociales et économiques du Bassin, lequel est marqué par des pratiques agricoles et d'élevage, principalement celles qui sont liées à la canne à sucre, aux pormes de terre et aux oignons, aussi bien qu' aux bovins. On a cartographié et analysé la géologie, la pédologie, le drainage, l'hypsonétrie, les pentes et l'ocapation des terrains, avec traitement en. SIG et intégration par un algorithme parr arriver à une carte synthèse des classes de fragi lité environnementale du Bassin. Alors, on a conclu que la plupart de l'aire formée par jonction des classes de moyenne à très haute fragi lité sont dans la portion de Serra da Mentiqueira - plus grand intensité des processus morphogéniques.

Mbts-clé: Bassin hydrographique, fragilité environnementale, Gécmonphologie, méthooblogie, Brésil.

\section{ABSTRACT}

This work presents a cartographic essay to determination of envircmental fragility in the watershed of the Rio Verde (SP) , localized in a contact area between crystalline rocks of the Serra da Mentiqueira and sedimentary terrains of the Depressão Periférica Paulista. 
Analyzed the historical-social-economic characteristics of the watershed, which is marked for the agrialture practices, principally, the connected with potato, onion, sugar cane planting, over there of livestodk creation. Mapped and analyzed about geology, pedology, drainage, hypsometric, declivities and terrain use and occupation dates, which went treatise in a SIG enviroment and integrated for a algorithm to arrive to a synthesis map of the fragility enviromental classes in the watershed.

Then, we conclude that the major part of area formed by adding the average classes to the very high fragility classes are in the portion of the Serra da Nentiqueira - major intensity of the monphogenetic process.

Key words: Drainage basin; envirarmental fragility; Ceomorfology; metodology, Brazil.

\section{Introdução}

O objetivo deste artigo é apresentar uma metodologia para o cálculo e conseqüente mapeamento da fragilidade ambiental, na bacia hidrográfica do rio Verde, que apresenta una área de $525,30 \mathrm{Km}^{2}$ e está situada na região nordeste do Estadb de São Paulo, Brasil (figura 1). Inicialmente partiu-se do conceito de fragilidade ambiental proposto por Ross $(1990$; 1996), onde acrescentamos índices morfométricos advindos do mapeamento de temas relacionadbs à geomorfologia fluvial. Posteriormente, os dados quantitativos foram integrados em uma equação, donde foi gerado um mapa de fragilidade ambiental para a bacia estudada.

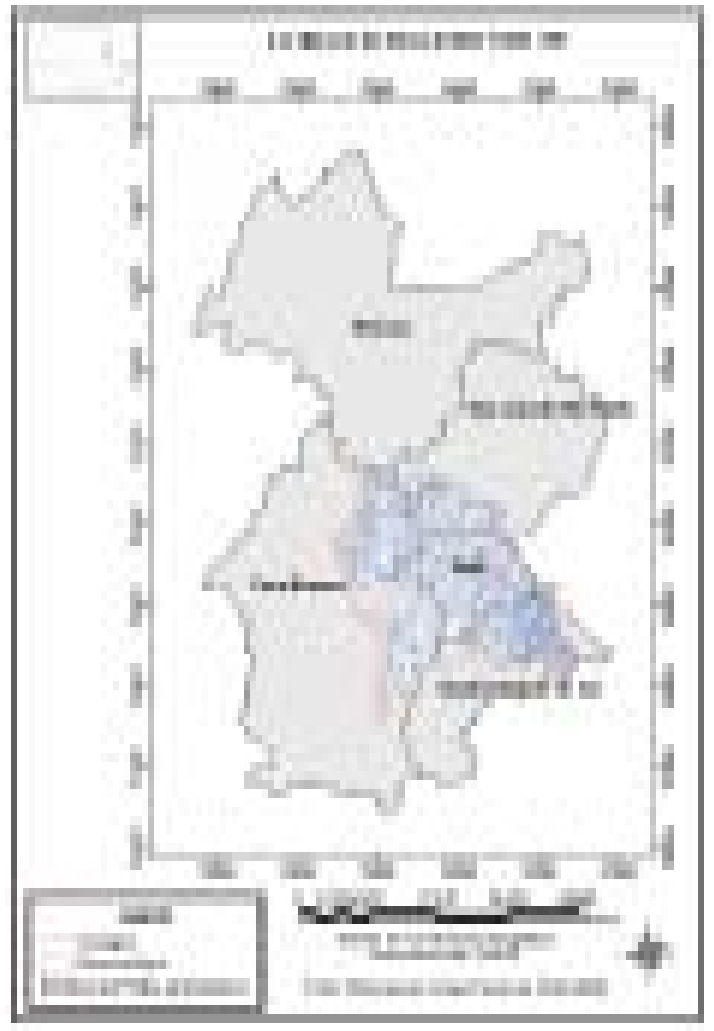

Fig. 1 - Localização da Bacia do Rio Verde.
Assim, esperamos contribuir para o desenvolvimento de novas metodologias de mapeamento da fragilidade dos ambientes antropizados e ao mesmo tempo contribuir para projetos e programas de planejamento e gestão ambiental, mais especificamente, abordando as usas da água dentro de uma concepção sistêmica de bacia hidrográfica e de arranjo geográfico.

\section{A Bacia Hidrográfica do Rio Verde em estado de criticidade}

A deliberação do Comitê da Bacia Hidrográfica do Pardo - CBH-PARDO 004/04 - declarou crítica a Bacia Hidrográfica do Rio Verde em 25/06/2004 . O estado de criticidade de uma bacia hidrográfica é caracterizadb combase no Artigo 14 da Lei Estadual n . 9.034, de 27/12/94, a qual dispõe sobre o Plano Estadual de Recursos Hídricos (PERH) e estabelece que, quando a soma das vazões captadas em uma determinada bacia hidrográfica, ou em parte desta, superar 50\% (cinqüenta por cento) da respectiva vazão de referência conforme determina o inciso II do Artigo 13 da mesma lei, ou seja, a vazão de referência para orientar a atorga de direitos de uso de recursos hídricos será calculada com base na média mínima de 7 (sete) dias conseautivos e 10 (dez) anos de período de retomo $(Q 7,10)$ e nas vazões regularizadas por reservatórios, descontadas as perdas por infiltração, evaporação ou por outros processos físicos, decorrentes da utilização das águas e as reversões de bacias hidrográficas.

Sendo assim, ainda conforme a Del iberação cBHPARDO 004/04, a Bacia do Rio Verde foi submetida ao regime especial de gerenciamento que deve levar en conta:

I o monitoramento da quantidade e qualidade dos recursos hídricos; de forma a permitir previsões que orientem o racionamento ou medidas especiais de controle de derivaçães de águas e de lançamento de efluentes; 
II a constituição de comissões de usuários, supervisionadas pelas entidades estaduais de gestão dos recursos hídricos, para o estabelecimento, em comum acordo, de regras de operação das captações e lançamentos;

III a obrigatoriedade de implantação, pelos usuários, de programas de racionalização do uso de recursos hídricos, com metas estabelecidas pelos atos de atorga.

Segundo TORNADORE (2004), membro do Conselho Estadual do Meio Ambiente de São Paulo, a Bacia do Rio Verde foi declarada em estado de criticidade, pois, a crescente demanda de água em função do uso, principalmente para irrigação, e sua reposição sem tratamento de esgoto sanitário e com resíduos químicos provenientes das práticas agrícolas vêm contribuindo para tal situação.

Com relação ao uso da água, um levantamento preliminar mostra que o Rio Verde tem um uso predominantemente agrícola: 90\% da demanda por água visamà irrigação; 8\%, o abastecimento público; e 2\%, outros usos (TORNDORE, 2004), além do que $80 \%$ da água utilizada na agricultura vão para a irrigação de plantaçães de batata e cebola. Porém, ainda não há uma idéia precisa da quantidade de agriaultores que se uti lizam da retirada de água.

Com relação ao tratamento do esgoto sanitário, segundo dados da Fundação Seade apresentados na TAвnA I, temos que o mesmo se mostra precário nos municípios por onde passa o Rio Verde, especialmente em Vargem Grande do Sul e Itobi ande o tratamento não existe, o que contrasta com 100\% do esgoto sani tário tratado no município de São João da Boa Vista (SP) , o qual é sede daquela Região de Govemo - que pertence à Região Administrativa de Campinas (SP) - e está localizado na Bacia do Mboi e por onde passa o Rio Jaguari Mirim.

Thwa I - Tratamento do Esgoto Sanitário (\%) (1992 - 2003)

\begin{tabular}{|lc|c|c|c|c|}
\hline \multicolumn{1}{|c}{ Localidade } & 1992 & 1995 & 1997 & 1999 & 2003 \\
\hline São João da Boa Vista & 5,00 & 10,00 & 18,00 & 100,00 & 100,00 \\
\hline Casa Branca & 25,00 & 10,00 & 5,00 & 2,00 & 20,00 \\
\hline São Jose do Rio Pardo & 6,00 & 10,00 & 17,00 & 15,00 & 15,00 \\
\hline Mococa & 0,00 & 0,00 & 3,00 & 1,00 & 2,00 \\
\hline Itobi & 0,00 & 0,00 & 0,00 & 0,00 & 0,00 \\
\hline Vargem Grande do Sul & 0,00 & 0,00 & 0,00 & 0,00 & 0,00 \\
\hline
\end{tabular}

Fonte: Fundação Seade - 2008. Elaborada por Juliano P. de Mello.
O Plano de Bacia - Pardo (Relatório final, 2003) enfatiza o pequeno percentual de tratamento de esgotos domésticos, com grande carga poluidora remanescente que é lançada nos corpos d'água, notadamente nas áreas de Mococa (>3000 kg de DBO5/dia) ${ }^{2}$, São José do Rio Pardo e Vargem Grande do Sul (>1500 kg de DBO5/dia) .

Segundb o Plano de Bacia - Parob (Relatório final, 2003) a demanda cadastrada para os mananciais Tambaú, Congonhas e Verde e para os Aqüíferos Cristalino e Tubarão está em tomo de 10,51\% em relação à disponibili idade de água superficial e subsuperficial, porém, a demanda estimada para tais mananciais está en tomo de 70,9\%, au seja, indicandb a necessidade de cadastrar de forma sistenática os usuários de água, notadamente para o uso de irrigação e nural, conseqüentemente apontandb para o uso crítico de águas superficiais para irrigação, além do que, ressaltando como fontes de poluição lixões e esgotos, e a poluição por cargas difusas associada a práticas agrícolas (agroquímicos).

Nas últimas décadas as problemas relacionados à degradação ambiental têm sido alvos da mobilização de dirigentes do setor público e de grupos representativos da sociedade civil (VIrIE, 1997). Com isso, reforça-se a necessidade da compreensão dos processos responsáveis, mais especificamente, pela degradação dos recursos hídricos, a fim de que se possa ter um entendimento sobre o porquê ela ocorre, e dessa forma poder associar o processo de ocupação e diferentes usos do território com a conservação dos mesmos, conseqüentemente, assegurando sua necessária disponibilidade para gerações presentes e futuras, com padrões de qualidade adequados aos usos.

\section{Caracterização da Bacia Hidrográfica do Rio Verde}

A Bacia Hidrográfica do Rio Verde localiza-se na Região Nordeste do Estado de São Paulo, Brasil e, passui suas nascentes na Serra da Mantiqueira, mais especificamente, no Município de Vargem Grande do Sul (SP) , drenandb os municípios de Itcbi (SP) , Casa Branca e São José do Rio Pardo (SP) , tendo sua foz no Rio Pardo na altura do município de Mbcoca (SP) . O Rio Verde constitui-se no único manancial superficial para os municípios de Vargem Grande do Sul (SP) e Itcoi (SP) , e suas nascentes encontram-se totalmente local izadas nas encostas da Serra da Fartura, ao norte do sítio urbano de Vargem Grande do Sul（SP) , mais precisamente na área da Fazenda Cafundó. 
Caracterização geológica

Segundo o PROJETO SAPUCAI (DNPM/CPRM, 1979) , a tectônica é o elemento primordial na formação do Planalto At lântico Brasileiro, do qual a Serra da Mantiqueira, onde se encontram as nascentes do Rio Verde, é o bloco mais elevado e interiorizado, porém, no contato com o planalto sul de Minas (superfície do alto Rio Grande) as evidências tectônicas são mascaradas pela intensa erosão diferencial.

A Serra da Mantiqueira é constituŕda de uma assembléia de termos petrográficos representada, basicamente por granitos e granitóides porfiroblásticos, migmatitos diversos (incluindo espécimes de médio e alto grau de metamórfico) , granulitos, micaxistos, "gnaisses", rochas cataclásticas e, subordinadamente, dolomitos, quartzitos, metabasitos, metaconglomerados, metaultrabasitos e rochas calcossilicáticas (DNPM) CPRM, 1979:33).

A zona cristal ina do Norte é constituŕda de rochas pré-cambrianas que mantêm um relevo de transição entre as terras altas do Planalto sul de Minas e da Mantiqueira para a região rebaixada da Depressão Periférica. Está subdividida em duas zonas de feições ligeiramente distintas: subzona de Amparo e subzona de São José do Rio Pardo.

A subzona de São José do Rio Pardo estende-se desde o nordeste de Mogi Guaçu (SP) e Pinhal (SP) até Jacuí do Norte. Seu relevo mostra-se mais movimentado, sobretudo a noroeste de Poços de Caldas (MG) , onde a tectônica é responsável pela elevação da superfície até níveis de 1550 metros. No restante da zona permanece a superfície Itaguá (550$720 \mathrm{~m}$ ), se bem que o relevo mais movimentado e dissecadb por vales vigorosos mascara esta superfície (DNPM/CPRM, 1979:35) .

A Depressão Periférica Paulista é escavada em rochas do Grupo Passa Dois, do Super-Grupo Tubarão e acompanha toda a frente do planalto sedimentar.

O Super-Grupo Tubarão, formado principalmentepor arenitos, tilitos, diamictitos e siltitos, evolui para um relevo de suaves colinas e amplos interflúvios esbatidos.

o contato das rochas sedimentares permocarboniferas que compõem a Depressão Periférica com as rochas do embasamento cristalino oferece áreas de điferentes resistências à ercosão fluvial, tendb, como conseqüência, o aparecimento, nesta zona de contato, de soleiras resistentes cortadas nas rochas do embasamento e formação de cachoeiras e corredeiras, caracterizando assima chamada "fall line" paulista (DNPM/CPRM, 1979:35-36) .
Segundo Aвसu (1972) , a zona de contato entre a Depressão Periférica Paulista e o Planalto Atlântico reúne características ímpares no território paulista, o que se pode depreender faci lmente através da anál ise de sua posição em relação à compartimentação geológica do Estado.

Pode-se constatar que os contrafortes ocidentais da Mantiqueira, no Estado de São Paulo, correspondem a um enorme arco, onde a morfogênese pode definir aquele arranjo particular de formas. Temos aí o imenso rebordo de um maciço antigo, para cuja gênese podemos lembrar as palavras de Ab'Saber (apud Antwu, 1972:8) :

"... Jáno centro sul de Minas Gerais, Norcleste de São Paulo e Estado do Rio de Janeiro, onde existe uma rede de drenagem radial irregular das mais notáveis encontradas nos velhos planaltos do Brasil - pode-se vislumbrar a presença de uma abóbada mito antiga, mito soerguida e muito complexa, a qual modemamente (fins do Terciário) foi atingida plenamente pelos efeitos da tectônica quebrável, tenob sido desfeita através de uma topografia acidentada de montanhas em bloco e fossas tectônicas (núcleo sul-ocidental ob Esabb Brasileiro). Trata-se, aliás, da única área de compartimentação topográfica predominantemente tectônica de todo o Planalto Brasileiro..., originadopelo contato entre terrenospré devanianos do núcleo sul-oriental do Esaubb Brasileiro e as rochas sedimentares, que a part ir do Paleozóico depositaram-se sobre este embasamento, definindo a Bacia Sedimentar do Paraná."

Antu (1972) ressalta que os estudas das contatos ente os maciços antigos e os sedimentos que os recobrem, possuem um lugar especial na Geomorfologia, uma vez que a convergência de estnuturas diferenciadas e seu arranjo espacial vão permitir o aparecimento de uma disposição singular de formas de relevo, sendo mesmo uma área-chave para a solução de problemas que afetam os dois grandes domínios geológicas.

Geologicamente, a área proposta no estudo de AसRu (1972) , a qual, em grande parte, coincide com a área da Bacia Hidrográfica do Rio Verde (SP) , caracteriza-se pela extrema diversificação de suas estruturas. Se os dois elementos fundamentais da geologia local, sedimentos paleozóicos pertencentes à Bacia do Paraná e os terrenos constituintes do núcleo sul-oriental do Escudo Brasileiro, chamados por AtMEIIAA (apud ABRH, 1972:11) de Maciço Atlântico, apresentam grande faixa de contato, mesmo se considerado apenas a porção que interessa ao Sudeste do Brasil em geral ou a São Paulo, em particular, o setor que nos propusemos investigar individualiza-se em função da intrusão alcalina de poços de caldas, que trouxe um novo elemento no 
arranjo regional das estruturas neste rebordo do maciço antigo. A esta intrusão devemos acrescentar os si77s, diques e lacólitos de diabásio que ocorreram com grande freqüência entre os terrenos sedimentares, no setor centro-norte deste contato, em São Paulo, conseqüentemente, sendo um dos trechos de maior diversificação estnutural de nosso Estadb.

Ressalta-se que a Bacia Hidrográfica do Rio Verde registra uma grande diversidade litológica, estrutural e geomorfológica resultantes da combinação geológica com eventos paleoclimáticas, sendo que, sua evolução e povoamento ocorreram numa zona de contato entre a Depressão Periférica Paulista e o Planalto Atlântico (Anसu, 1972) .

Segundo ArRE (1972) , a paisagem do contato entre os terrenos pré-devonianos do leste paulista e as séries basais dos sedimentos gondwânicos, conforme o mapa geológico (fig. 2) e a TABrA II revelam, apresentam contrastes resultantes da alteração das condiç̧̃es litológicas/gecmorfológicas que se qperam ali, as quais têm suas conseqüências nas atividades humanas e seus reflexos na organização regional do espaço.

TABHA II - Unidades Geológicas da Bacia Hidrográfica do Rio Verde (SP)

\begin{tabular}{|l|c|c|}
\hline \multicolumn{1}{|c|}{ Unidades } & Área $\left(\mathrm{km}^{2}\right)$ & Porcentagem $(\%)$ \\
\hline Complexo Pinhlal & 213,70 & 40,70 \\
\hline Complexo Alfenas-Guaxupé & 47,60 & 9,05 \\
\hline Complexo Caconde & 3,50 & 0,70 \\
\hline Grupo São Bento - Formacão Serrra Geral & 11,67 & 2,20 \\
\hline Grupo Tubarão & 161,35 & 30,70 \\
\hline Depósitos Cenoźócos & 87,48 & 16,65 \\
\hline TOTAL & 525,30 & 100 \\
\hline
\end{tabular}

Fonte: Plano de Bacia - Pardo (Relatório final, 2003) . Elaborado por Juliano Pereira de Mello.

Aprev (1972) enfatiza que a combinação dos fatores estruturais e topográficos individualiza profundamente a área estudada, fazendo com que além de um rebordo de maciço antigo, ela seja também uma área de transição geológica, apresentando-nos não só um mosaico de formas de relevo, mas também aspectos bioclimáticos contrastantes.

Além disso, a convergência de todos estes elementos deve ser associada ainda, ao fato da Bacia Hidrográfica do Rio Verde (SP) estar situada emuma posição extremamente complexa junto dos domínios morfoclimáticos brasileiros (AसRु, 1972) encontrando-se na transição entre os chapadões florestadbs, característicos do centro-ceste paulista e as áreas tipicamente mamemolizadas, de vertentes policonvexas, do sul de Minas, ambas integradas no Domínio dos Mares de Morros, de caráter azonal,

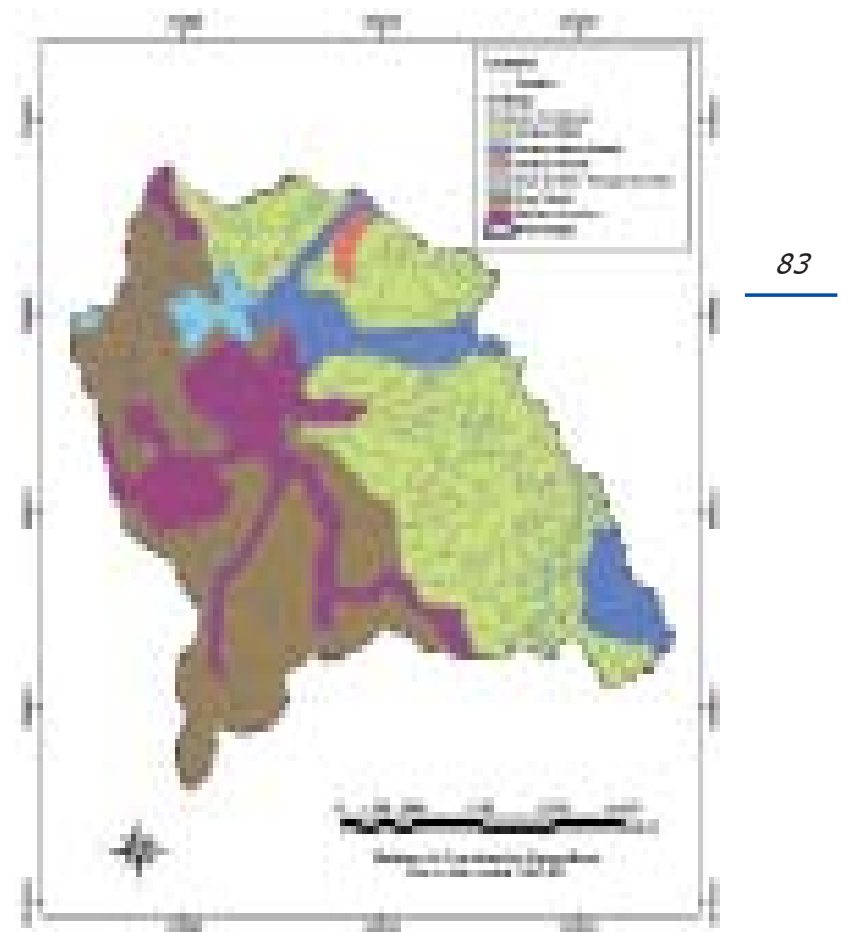

Fig. 2 - Mapa Geológico - Bacia hidrográfica do Rio Verde (SP) .

Fonte: Plano de Bacia - Pardo (Relatório final, 2003) .

Elaborado por Juliano Pereira de Mello (2008) .

esta região apresenta ainda aspectos que a vinculam à faixa de transição para o domínio dos cerradbs, zonal, possuindo em certos compartimentos um fáceis gececológico que a liga a este donínio.

Estamos, portanto, diante de una área arjo mosaico paisagístico e gececológico é extremamente complexo, na estruturação do qual se associaram fatores bioclináticos zonais e azonais, atuanob sobre umarcabousco estrutural de tal ordeme trabal handb en sua retaguarda de tal maneira, que encontramos aqui uma quase síntese paisagística do Estadb (Aमrve, 1972:12) .

\section{Um contato geológico-geomorfológico de disposição simples}

A paisagem do contato entre os terrenos prédevonianos do leste paulista com as séries basais dos sedimentos gondwânicos, nas proximidades de Vargem Grande do Sul revela os contrastes resultantes da alteração das condições litológicas. Há que se registrar as conseqüências destas mudanças na estruturação das atividades humanas e seus reflexas na organização regional do espaço (A\#+ు, 1972:88) .

Segundo Arसu (1972), na área de ocorrência de contato entre rochas do embasamento e sedimentos paleozóicos encontramos depósitos de sedimentos modernos ao longo das várzeas e alvéolos, sendo que nos arredores de Vargem Grande do sul eles 
adquirem maior expressão; temos aí calhas aluviais relativamente amplas que envolvem a cidade com material detrítico (foto 1) originadona "old land" e depositados em grande quantidade neste trecho devido à ruptura de declive operada nos perfis longitudinais dos cursos d'água ao ingressarem na Depressão Periférica. Nas proximidades de Vargem Grande do Sul esse material vai ter grande importância para a indústria cerâmica (foto 2), a qual atende, principalmente, às demandas da Região de Governo de São João da Boa Vista. Além do que, o próprio nome da cidade é bastante significativo e evoca a existência de tais sedimentas depasitados por cursos que penetram na Depressão em condições de rios conseqüentes ou resseqüentes.
Köeppen) em que a temperatura média do mês mais frio está en tomo de $17,7^{\circ} \mathrm{C}$ (julh) e a do mês mais quente ultrapassa $23^{\circ} \mathrm{C}$ (fevereiro) .

Além disso, conforme as informações do quadro 5, o total de chuvas do mês mais seco não ult rapassa 21, $5 \mathrm{~mm}$.

A estação seca nessa região ocorre nos meses de abril a setembro, sendo agosto o mês em que atinge a méxima intensidade. O mês mais chuvoso ascila entre dezenbro, janeiro e fevereiro. A temperatura média do mês mais quente oscila entre $23^{\circ} \mathrm{Ce} 24^{\circ} \mathrm{C}$ (Thस्HA III) .

Para a caracterização pluviométrica da Bacia Hidrográfica do Rio Verde (SP) foram utilizadas as dados pluviométricos do posto C3-009 - Vargem Grande do Sul, cuja altitude está em tomo de $750 \mathrm{~m}$ e situa-se na latitude 21050'S e longitude 4654' . Foi

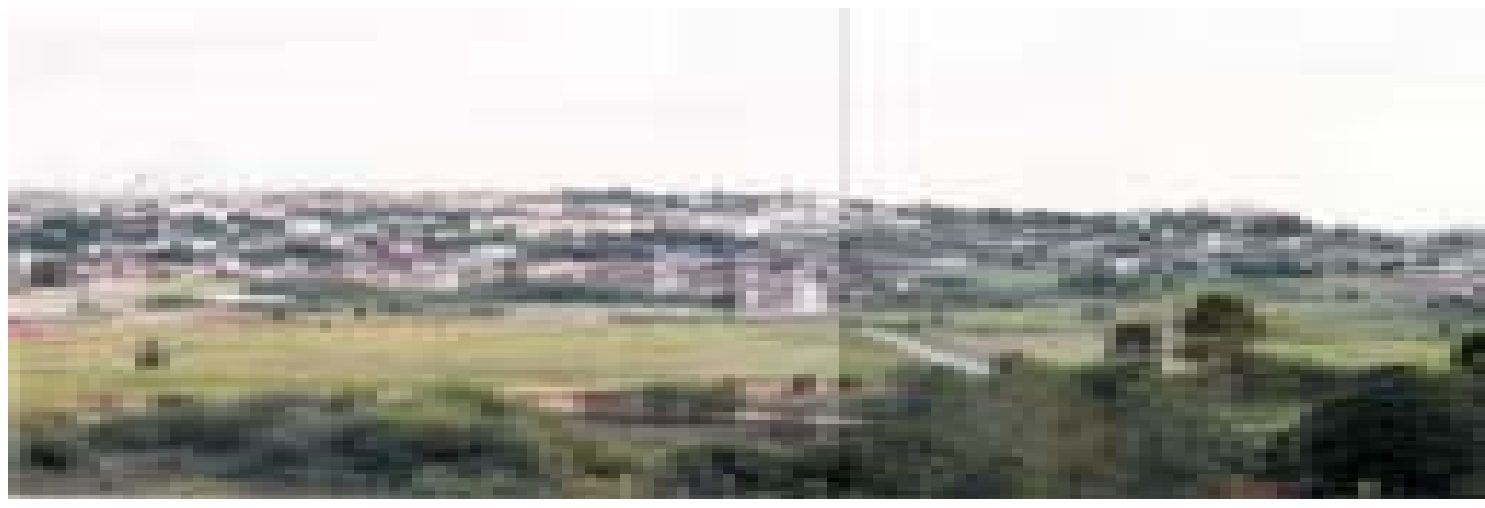

Fot. 1 - Áreas de várzea - Vargem Grande do Sul (SP)

Obs. : Vista panorâmica das áreas de várzea às margens do rio Verde. As fotografias para esta montagem foram tiradas a partir da visada do Bairro Fortaleza, Vargem Grande do Sul (SP). Fonte: Fotos do autor, 19/08/2007.

\section{Caracterização climática}

Segundo o Centro de Pesquisas Meteorológicas e Climáticas Aplicadas à Agricultura (CFPAGRI) ${ }^{3}$, a área da Bacia Hidrográfica do Rio Verde é caracterizada pelo clima temperado úmido, com Invemo seco e Verão (Cha - Sistema Intemacional de

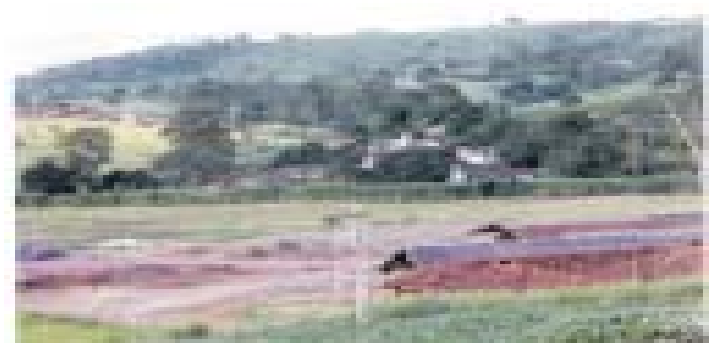

Fot. 2 - Área de extração de argila - Vargem Grande do Sul (SP)

Obs. : Cava de argila para abastecimento de atividade ceramista às margens do rio Verde e próximo ao sítio urbano de Vargem Grande do Sul (SP) . Fonte: Foto do autor, 19/08/2007.
Thw1 III - Resumo das Características Climáticas - Bacia Hidrográfica do Rio Verde

\begin{tabular}{|c|c|c|c|c|}
\hline \multicolumn{5}{|c|}{ Classificação Climática de Koeppen: Cwa } \\
\hline \multirow{4}{*}{ MÊS } & mínima média & máxima média & média & \\
\cline { 2 - 5 } & TEMPERATURA DO AR $\left({ }^{\circ} \mathrm{C}\right)$ & CHUVA (mm) \\
\hline JAN & 18.1 & 29.1 & 23.6 & 260.5 \\
\hline FEV & 18.3 & 29.2 & 23.7 & 190.3 \\
\hline MAR & 17.5 & 28.9 & 23.2 & 161.1 \\
\hline ABR & 15.0 & 27.6 & 21.3 & 73.2 \\
\hline MAI & 12.3 & 25.8 & 19.0 & 52.7 \\
\hline JUN & 10.9 & 24.7 & 17.8 & 28.3 \\
\hline JUL & 10.4 & 25.0 & 17.7 & 24.9 \\
\hline AGO & 11.8 & 27.2 & 19.5 & 21.5 \\
\hline SET & 13.9 & 28.4 & 21.2 & 69.2 \\
\hline OUT & 15.6 & 28.7 & 22.1 & 138.3 \\
\hline NOV & 16.4 & 28.8 & 22.6 & 176.8 \\
\hline DEZ & 17.5 & 28.6 & 23.0 & 254.4 \\
\hline \multicolumn{5}{|c|}{} \\
\hline Ano & 14.8 & 27.7 & 21.2 & 1451.2 \\
\hline Mínima & 10.4 & 24.7 & 17.7 & 21.5 \\
\hline Máxima & 18.3 & 29.2 & 23.7 & 260.5 \\
\hline
\end{tabular}

Fonte: http://www.cpa.unicamp.br/outras-informacoes/ Clima_muni_635.html. Consulta em 15/12/2007. 
escolhido para o estudo dos índices pluviamétricos da bacia o período de 1960 a 2004. A partir dos dados dos totais pluviométricos mensais foram calculados os totais anuais e as médias mensais para o período de 1960 - 2004 (fig. 3) .

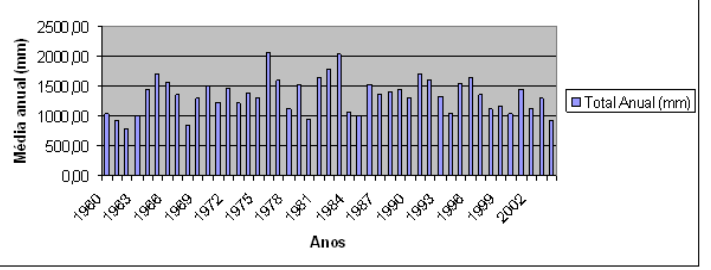

Fig. 3 - Totais Pluviométricos Anuais para a Bacia do Rio Verde (SP) - 1960 a 2004.

Fonte: http: //www.sigrh. sp.gov.br/cgi-bin/lodlm. exe/plu. Consultado em 20/01/2008.

Assim, podemos afimar que os anos de maior fenômenopluviométrico total coorreramem 1976, comumvalor de 2058, 30 me 1983 com 2034,30 m (fig. 3) e que as anos de maior fenômeno pluviométrico média/mensal ocorreram em 1961, com valor médio alcançandb cerca de 155, 4 m/mês, 1976 cam valor médio de 171, 5 m/ mês e 1983 comvalor médio de 169,5 m/mês (fig. 4) .

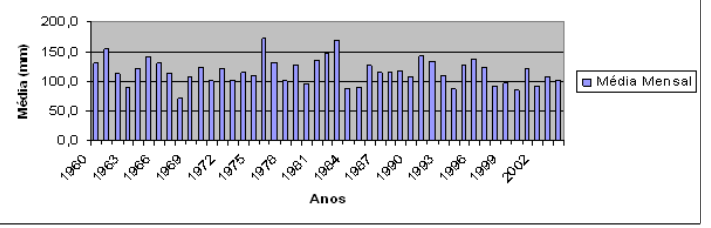

Fig. 4 - Precipitação Média Mensal (m) (1960 - 2004) .

\section{Relações entre o processo de povoamento, o uso das terras e a compartimentação geamorfológica na bacia do Rio Verde.}

Conforme ressaltado por Aвpu (1972), o Rio verde apresenta extensas áreas de várzeas e com seu traçado sinuoso delimita a transição entre os Ecossistemas da Serra e dos Campos Cerrados no Nordeste do Estado de São Paulo, onde a ocupação urbana e agrícola de Vargem Grande do Sul teve início na segunda metade do século XIX.

Aнस्U (1972: 88-89) enfatiza a organização do povoamento, sua densidade e dinamismo, o que melhor revela as atitudes tomadas pela população local face aos compartimentos morfo-estnuturais da área do município de Vargem Grande do Sul. Sendo que, o povoamento nural, primeiramente, concentrouse nos terrenos cristalinos, tomandb-se menos denso sobre os sedimentares; o povoamento urbano, contudb, definido no contato das dois damúnios, scbre o enbasamento, cresce preferencialmente em direção às áreas sedimentares.

A análise do sítio urbano de Vargem Grande do Sul demonstra-nos uma série de fatos significantes. Tendb-se originado sdore o interfllúvio, já próximo da confluência do Ribeirão Santana com o Rio Verde, assentandb-se em seu início sobre o pequeno "replat", o núcleo urbano apresentava-se, de certa forma, com reduzidas possibilidades de expansão. A leste, as terrenos tomam-se dissecadbs e cheios de dostáarlos, a norte, sul e ceste a cidade é envolvida por várzeas relativamente amplas e sujeitas a cheias. Contudb, 0 significado dos dois dostáculos é diferente, pois superada a várzea surgem terrenos mais propícios à utilização urbana, portanto, transpostas as duas várzeas, a cidade elegeu as colinas de relevos tabul iformes da Depressão Perifiérica como direções preferenciais de expansão (AвRE, 1972:89) . Atualmente, a área unbana ocupa as duas vertentes do interflúvio sdore o qual se originare já conquistau as vertentes de além-várzea, iniciando agora a ocupação das faces opostas a estas segundas, em plena área sedimentar. Uma dessas direções, aliás, foi inclusive reforçada pela presença da rodovia, asfaltada hoje, que une Casa Branca a São João da Boa Vista, passando por Vargem Grande do Sul.

Conforme ABREU (1972:89), a situação do povoamento rural é bastante diferente, pois, em primeiro lugar, ampre ressaltar na área a existência de formas dispersas e agnupadas, embora a primeira predomine largamente e apresente-se nitidamente orientada pela drenagem, sendo exemplos características as definidos ao longo dos vales do Rio Verde e Ribeirão Santana, a leste de Vargem Grande do Sul. Nestes dois vales citados pode-se, igualmente, perceber a posição das construções, predominantemente na baixa encosta, em plano ligeiramente superior ao da várzea, correspondendo de um modo geral a pequenas propriedades rurais que têmnas terras da várzea, através da rizicultura ou do plantio de cebolas e batatas, um dos trechos valorizados de seus solos (Aнस्य, 1972:89) .

Além do povoamento linear disperso ao longo dos vales, encontramos ainda autro tipo de dispersão, que Arpeu (1972:89-90) chama de nodular, a qual embora ligada à drenagem não se enquadra no primeiro caso. Esta segunda modalidade, em geral, apresenta construçães localizadas em pontos mais elevados das vertentes e inclusive, correspondendo com certa freqüência a cabeceiras de drenagem. É um tipo associado a propriedades rurais de maior extensão e a disposição das casas revela, às vezes, a antiga fazenda cafeicultora com a típica "colônia", como ocorre a nordeste de Vargem Grande do Sul, e que foi largamente substituída pelas pastagens. 
O povoamento nural concentrado surge no sudeste da área, já no contato da Bacia do Rio Verde com a Bacia do Jaguari-Mirim é representado pelo bairro Pedregulho, o qual pertence ao município de São João da Boa Vista, e arjo topônimo lembra a presença dos cascalhos e matacões que ocorrem com grande freqüência na região (Аस⿴囗十, 1972:90) .

No trecho sedimentar A redução do povoamento, que se rarefaz ainda mais a oeste da região, porém, a partir da década de 1980, há que se ressaltar o surgimento e consolicação de vários bairros tomando-o um eixo da expansão urbana do município ao longo da Rodovia que liga Vargem Grande do Sul à Casa Branca.

Segundo Amu (1972), attro fato que reflete para ao observador as mudanças estruturais é o recobrimento vegetal que veio sofrendb alto grau de alteração pela intervenção humana. Os terrenos cristalinos do leste, a julgar pelos remanescentes que se encontram dispersos, os quais regridem à medida das atividades humanas, sugerem um pretérito recobrimento vegetal extensivo desde a "old land" pela Mata Tropical Atlântica, com caráter semidecído, inicialmente substituŕda pela cafeicultura, o que, é confirmado pelas estatísticas agrícolas do início do século passado (1909) , que davam para Vargem Grande do Sul, então distrito de São João da Boa Vista, 1.154.700 cafeeiros. Esse total engldba dados de São Roque da Fartura (atualmente pertencente a Águas da Prata) e São Sebastião da Grama (hoje município) e torna claro o papel representado por este produto no desmatamento general izado que hoje se dbserva na região.

Os terrenos sedimentares a oeste da bacia hidrográfica são caracterizadbs pelo cerradb, o qual, vem sendo igualmente reduzido e empobrecido pela ação antrópica. Os cerrados localizados a sudeste de Vargem Grande do Sul são extremamente raquíticos, com ardoustos muito pequenos e utilizados camo pastagens extensivas e, como ressaltado por Aнसu (1972:91), seu aspecto degradado é resultado de um prolongado processo de exploração pelo homem, sendo que em sua maior parte ocorre no interflúvio Jaguari-Mirim-Rio Verde, em cotas entre 650-720 metros, estando as várzeas dos rios citados abaixo de 630 metros. Ressaltamos que a ocupação agrícola no Município de Vargem Grande do sul partiu da região da Serra da Fartura em função da presença das nascentes, inclusive as do Rio Verde, pois, a água era e continua sendo elemento de suma importância para o agricultor. Fra fonte da força motriz empregada nas maquinarias de tulha, monjolos e serrarias. E, com o advento da lavoura cafeeira passa a ser amplamente utilizada no beneficiamento ena classificação das diversas tipologias do café.

Segundo matéria publicada na "Gazeta de Vargem Grande" (24/07/1994) , no início do uso e ocupação do território de Vargem Grande do Sul, a relação ecológica entre o agricul tor e o meio teve um caráter não predatório, au seja, pautava-se por um equilíbrio, no qual, protegia-se a mata natural das nascentes e a mata ciliar a fim de preservar a água,

TABeta IV - Uso e Ocupação da Terra (1998 a 2002/2003)

\begin{tabular}{|c|c|c|c|c|c|c|c|c|c|c|}
\hline \multirow[t]{2}{*}{ Município } & \multicolumn{2}{|c|}{ Área Urbana } & \multicolumn{2}{|c|}{ Fruticultura } & \multicolumn{2}{|c|}{ Café } & \multicolumn{2}{|c|}{ Cana-de-açúcar } & \multicolumn{2}{|c|}{$\begin{array}{c}\text { Cultura } \\
\text { Anual* } \\
\text { (sem irrigação) }\end{array}$} \\
\hline & $\begin{array}{c}-1988 \\
\text { (há) } \\
\end{array}$ & $\begin{array}{c}(2002 / 2003) \\
\text { (ha) }\end{array}$ & $\begin{array}{c}-1988 \\
\text { (ha) } \\
\end{array}$ & $\begin{array}{c}(2002 / 2003) \\
\text { (ha) }\end{array}$ & $\begin{array}{c}-1988 \\
\text { (ha) } \\
\end{array}$ & $\begin{array}{c}(2002 / 2003) \\
\text { (ha) }\end{array}$ & $\begin{array}{c}-1988 \\
\text { (ha) } \\
\end{array}$ & $\begin{array}{c}(2002 / 2003) \\
\text { (ha) }\end{array}$ & $\begin{array}{c}-1988 \\
\text { (ha) }\end{array}$ & $\begin{array}{c}(2002 / 2003) \\
\text { (ha) }\end{array}$ \\
\hline Casa Branca & 973 & 1.201 & 10.491 & 17.926 & 626 & 73 & 7.874 & 37.084 & 22.410 & 0 \\
\hline Itobi & 102 & 145 & 0 & 0 & 33 & 0 & 151 & 4.156 & 3.400 & 0 \\
\hline Mococa & 1236 & 1.978 & 569 & 2.062 & 2.849 & 2.939 & 11.191 & 26.843 & 2.068 & 3.623 \\
\hline $\begin{array}{c}\text { São José do Rio } \\
\text { Pardo }\end{array}$ & 710 & 1.456 & 0 & 0 & 1485 & 0 & 291 & 6.362 & 1.868 & 1.113 \\
\hline $\begin{array}{c}\text { Vargem Grande do } \\
\text { Sul }\end{array}$ & 834 & 834 & 79 & 184 & 35 & 230 & 6.084 & 9.219 & 4.356 & 1.190 \\
\hline TOTAL & 3855 & 5.614 & 11.139 & 20.172 & 5028 & 3242 & 25.591 & 83.664 & 34.102 & 5926 \\
\hline \multirow{2}{*}{ Município } & \multicolumn{2}{|c|}{$\begin{array}{c}\text { Cultura Anual* }_{\text {de irrigação) }} \\
\text { (Pivô }\end{array}$} & \multicolumn{2}{|c|}{ Silvicultura } & \multicolumn{2}{|c|}{ Pastagem } & \multicolumn{2}{|c|}{ Vegetação Natural } & \multicolumn{2}{|c|}{ Vegetação Ripária } \\
\hline & $\begin{array}{c}\text { (1988) } \\
\text { (há) }\end{array}$ & $\begin{array}{c}(2002 / 2003) \\
\text { (ha) }\end{array}$ & $\begin{array}{c}\text { (1988) } \\
\text { (ha) }\end{array}$ & $\begin{array}{c}(2002 / 2003) \\
\text { (ha) }\end{array}$ & $\begin{array}{l}\text { (1988) } \\
\text { (ha) }\end{array}$ & $\begin{array}{c}(2002 / 2003) \\
\text { (ha) }\end{array}$ & $\begin{array}{c}\text { (1988) } \\
\text { (ha) }\end{array}$ & $\begin{array}{c}(2002 / 2003) \\
\text { (ha) }\end{array}$ & $\begin{array}{c}\text { (1988) } \\
\text { (ha) }\end{array}$ & $\begin{array}{c}(2002 / 2003) \\
\text { (ha) }\end{array}$ \\
\hline Casa Branca & 1.376 & 8.143 & 8.555 & 6.094 & 18.754 & 1.224 & 2.588 & 2.196 & 11.724 & 11.572 \\
\hline Itobi & 0 & 743 & 0 & 105 & 7.340 & 5.807 & 1.007 & 950 & 1.717 & 1.870 \\
\hline Mococa & 0 & 1.264 & 135 & 22 & 47.504 & 27.285 & 10.775 & 9.221 & 8.198 & 9.240 \\
\hline $\begin{array}{c}\text { São José do Rio } \\
\text { Pardo }\end{array}$ & 0 & 500 & 0 & 102 & 27.460 & 22.059 & 5.676 & 5.559 & 3.826 & 4.058 \\
\hline $\begin{array}{c}\text { Vargem Grande do } \\
\text { Sul }\end{array}$ & 100 & 1475 & 599 & 209 & 9.869 & 8.564 & 997 & 997 & 3.375 & 3.383 \\
\hline TOTAL & 1.476 & 12.125 & 9.289 & 6.532 & 110.927 & 64.939 & 21.043 & 18.923 & 28.840 & 30.123 \\
\hline
\end{tabular}


além do que, também não eram derrubadas as matas de encostas, coma finalidade de proteger os cafezais das geadas. Em 1929, com a crise do café e o abandono das terras nos primeiros anos devido aos escassos capitais, começa a penetrar na região a pecuária leiteira, favorecendo o desmatamento para a formação de pastos. Sendo assim, rompendo-se a relação de maior equilíbrio que perdurrou durante o ciclodb café.

Oprocesso de desmatamento foi intensificado nos anos de 1960 com a introdução das culturas mecanizadas de soja e batata nas áreas pertencentes ao danínio da Depressão Periférica, onde, us cerradōes foram substituŕdos pelas culturas irrigadas e, posteriormente, pela monocultura da cana-de-açúcar.

Na Th\# IV são apresentadas as áreas em hectares das dez classes de uso e ocupação da terra mapeadas segundo trabalho realizado por QuARIAROI et al. (2006) , no qual, mais uma vez, ressalta-se o uso agrícola, em especial, o aumento da área plantada de cana-de-açúcar em 58.073 ha (+227\%) , bem como, o de culturas anuais irrigadas em 10.649 ha (+721\%), no período de 1988 a 2002/2003 (Embrapa, Mbnitoramento por Satélite, 2006) , além do que, de maneira geral, a diminuição da vegetação natural, no mesmo período, em 2.120 ha, ou seja, em 10,1\% , porém, chamando à atenção para um aumento total da vegetação ripáría de 1.283 ha, ou seja, em 4,45\%.

\section{Resultados e análises}

Apresentamos como resultados utilizados na confecção final do mapa de fragilidade potencial o mapeamento da drenagem, da classificação da hierarquia fluvial, das características morfométricas (classes de declividade e compartimentação hipsométrica/MDI) , da geologia, das classes de solo e do uso e ocupação da terra.

Para delimitarmos o divisor d'água da bacia hidrográfica do Rio Verde, bem como, construirmos os mapas da hierarquia fluvial, das classes de declividade, compartimentação hipsométrica e do modelo digital do terreno, fizemos uso de quatro folhas topográficas do IBGE ${ }^{*}$ na escala 1:50.000 (Folha São José do Rio Pardo, 1970; Folha Casa Branca, 1971; Folha Rio Tambaú, 1971; Folha São João da Boa Vista, 1972) articuladas conforme quadrículas seguintes, que recobrem a área da bacia hidrográfica do Rio Verde (fig. 5) .

As cartas citadas foram dbtidas no site do IBGE en formato Tag Image File Format (TIFF) e Portable Document Format (PDF), sendo que as de formato PDF também foram transformadas em formato TIFF. Posteriormente, as cartas foram inseridas no Sistema

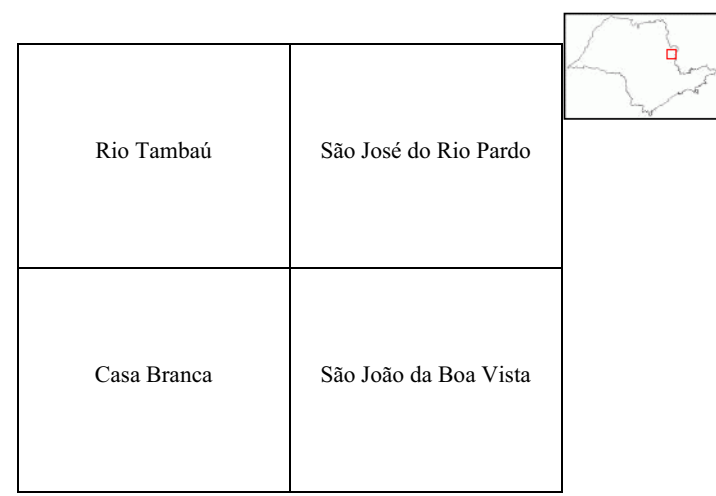

Fig. 5 - Articulação das Folhas Topográficas

de Informação Geográfica (SIG) Arc Mạo 9.1 e, em seguida, geo-referenciadas e digitalizadas com relação às arvas de nível, pontos cotadbs, canais de drenagem e nascentes.

O mapa geológico da bacia hidrográfica do Rio Verde foi construído a partir do mapa do PIANO DE BACIA - PARDO (RET ATÓRIO FTNAL) (2003) , o qual, assim como o mapa pedológico obtido no trabalho de QARIIRar et al. (2006), foram inseridos no SIG Arc Map 9.1 em formato TIFF, geo-referenciados e digitalizados conforme as estruturas geológicas e pedológicas presentes na área da bacia hidrográfica. Estamos prosseguindo com a digitalização do mapeamento do uso e ocupação da terra da Bacia Hidrográfica do Rio Verde em ambiente SIG (sistema de informação geográfica) levando em consideração o período de 1988 a 2002 conforme trabalho apresentado por QARrIARdi et al. (2006) .

\section{Drenageme hierarquia fluvial}

Segundo ABREu (1972:27-28), o Rio Verde apresenta sua rede de drenagem dividida entre os terrenas cristal inos e os terrenos sedimentares, ande, emprimeiro lugar, nota-se a diminuição de controles estruturais, para a maior parte dos canais e, em seguida, a mediocridade da maior parte das divisores d'água, os quais, com raras exceções, apresentam aspectos de colinas de topos tabuliformes. Assimé que os rios provenientes das terras pertencentes à Mentiqueira Ocidental, ao penetrarem nos terrenos sedimentares da Depressão Periférica, mudam a direção de seus cursos, passando a revelar outro padrão, como é o caso do Rio Verde, em seu médio e baixo arrso.

Conforme Aнसu (1972:29-30), outro aspecto que individual iza a porção do rebordb ocidental da Serra da Mantiqueira na área da Bacia Hidrográfica do Rio Verde, quando comparada com os terrenos

Folhas abtidas no site do IBCE (Www.ibge.gov.br) em formato TIFF e PDF em 15/01/2007. 
cristalinas do leste, é a forma dos vales, que agora são amplos, com rios meândricos, em fundas de vales freqüentemente ocupados, nas cartas topográficas, cam símbolos de vegetação de brejo.

Por meio de uma caracterização global dos padrões de drenagem, Аससu (1972:30) distinguiu, de um ladb, o setor sedimentar e, de autro, o cristal ino, sendo que neste último está evidente a presença de uma área bem individualizada, representada pela intnusão alcal ina que originar as estruturas do Planalto de Poços de caldas e que introduzirram um novo padrão de comportamento nas rochas cristal inas encaixantes.

Segundo CARISTOFAitir (1980:106), a hierarquia fluvial consiste no processo de se estabelecer a classificação de determinado arrso d'água (au da área drenada que the pertence) no conjunto total da bacia hiołrográfica na qual se encontra, o que é realizado em função de facil itar e tomar mais dojetivo os estudbs morfonétricos (análise linear, areal ehipsonétrica) .

Na presente definição da hierarquia fluvial adotamos o sistema de classificação introduzido por

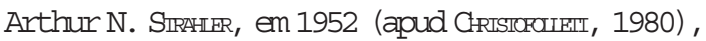
no qual, os menores canais, sem tributários, são considerados como de primeira ordem, estendendo-se desole a nascente até à confluência; os canais de segunda ordem surgem da confluência de dois canais de primeira ordem, e só recebem afluentes de primeira ordem; os canais de terceira ordem surgem da confluência de dbis canais de segunda ordem, podendb receber afluentes de primeira e de segunda ordens. E assim, sucessivamente.

Sendo assim, procedemos à classificação da hierarquia fluvial na Bacia Hidrográfica do Rio Verde da seguinte maneira:

$1^{\circ}$ - Fazendo uso do conjunto das cartas topográficas (em formato digital) inseridase geo-referenciadas no SIG Arc View (9.1), digitalizamos/vetorizamos todas as canais da bacia hidrográfica em questão;

$2^{\circ}$ - Na medida em que os canais iam sendo digital izados procedemos às suas respectivas classificações conforme STRAHLR (1952), conseqüentemente, criando uma tabela no banco de dados do SIG Arc View (9.1) de correspondência entre a linha que representa o canal e o número de sua ordem.

conforme a Thma V e o respectivo mapa da hierarquia fluvial (fig. 6) chamamos à atenção para a predominância dos canais de primeira ordem - 76, 30 \% (fig. 7) , as quais, foram colocados em vermelho para melhor visual izarmos a distribuição espacial dos mesmos.

Ressaltamos a concentração espacial dos canais de primeira ordem (fig. 6) nos terrenos cristalinos dabacia hidrográfica, onde, configura-se área de mananciais/ nascentes, au seja, de exfiltração do lençol freáticoe, conseqüentemente, caracterizandb-a como sendb de alta susceptibilidade a processos morfogenéticos.

TABEIA V - Classificação da Ordem dos canais de drenagem Bacia Hidrográfica do Rio Verde (segundo Arthur N. STRRHER, 1952)

\begin{tabular}{|c|c|c|}
\hline Ordem & Número de canais & Porcentagem (\%) \\
\hline 1 & 486 & 76,30 \\
\hline 2 & 112 & 17,60 \\
\hline 3 & 32 & 5,00 \\
\hline 4 & 6 & 0,94 \\
\hline 5 & 1 & 0,16 \\
\hline Total & 637 & 100 \\
\hline
\end{tabular}

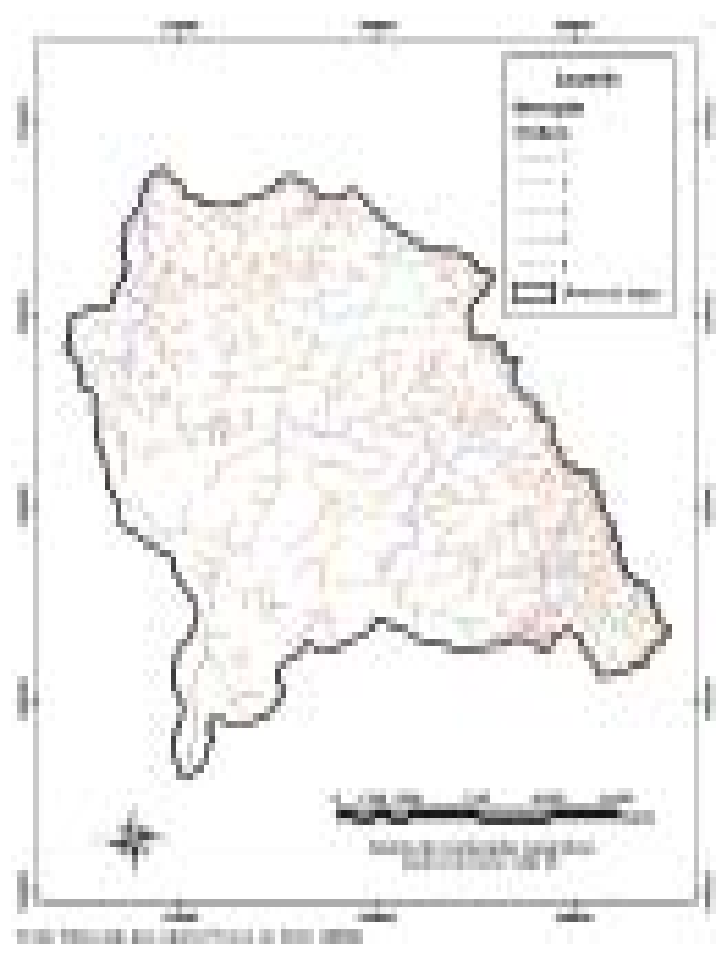

Fig. 6 - Mapa da Hierarquia Fluvial Bacia Hidrográfica do Rio Verde (SP) .

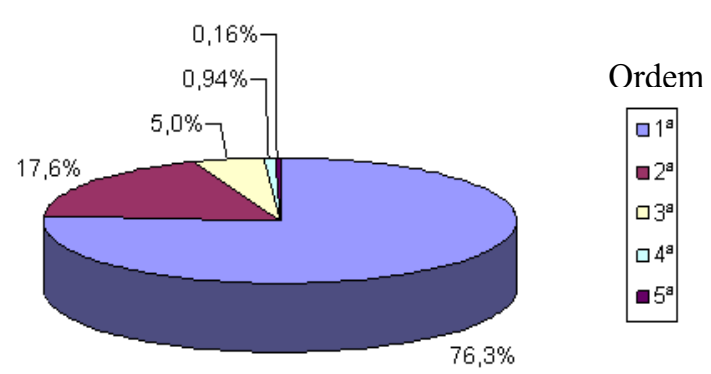

Fig. 7 - Distribuição Percentual da Hierarquia Fluvial (Bacia hidrográfica do Rio Verde) .

Ao analisarmos a drenagem em relação ao mapa geológico (fig. 6) percebemos, assim como ABRE (1972) ao estudar a bacia hidrográfica do Rio Jaguari, que a drenagem densa sobre as terrenas do 
embasamento cristalino, a qual, é marcada pela maior presença dos canais de primeira ordem, acaba por se tornar reduzida nas áreas sedimentares sugerindo uma permeabilididade maior destas rochas.

Aस⿴囗十 (1972) enfatiza que a disposição dos rios e seus formadores revelam alguns fatos característicos de um setor de "old-land", com uma longa história fisiográfica. Assim é que as direções de fraqueza, representadas por diaclasamentos, ou mesmo direções estruturais de outra natureza, estão claramente refletidas na orientação da drenagem, o que talvez explique a relativa freqüência de disposiçães ortogonais em junçães de aursos d'água, especialmente em rios e sulcos coletores temporários de categoria inferior, fato bastante nítido, por exemplo, na área localizada a nordeste de Vargem Grande do Sul. É ainda aí, através de freqüentes encaixamentos e numerosas rupturas no perfil longitudinal dos rios, que vamos registrar a presença de vales predominantemente em "V", os quais se tornam cada vez mais fechados a montante. A existência de corredeiras, aliás, é característica aparecendo em toda a área.

A análise do interflúvio entre o Jaguari-Mirimeo Rio Verde, conforme observa Arसu (1972), permitenos compreender relativamente bem a disposição geral do relevo e das estnuturas nesta região. Éum divisor d'águas orientado, grosso modo, de ceste para leste, quase perpendicular ao contato das duas grandes unidades morfo-estruturais em questão: Planalto Atlântico e Depressão Periférica. O setor cristalino apresenta-se bastante dissecado, com vales em " $\mathrm{Vl}$ " fechados e vertentes freqüentemente coalhadas de matacões. No setor ceste do contato supracitado, sua declividade diminui ainda mais e as vertentes apresentam drenagem pobre com vales amplos. De um lado temos o domínio das colinas de topos tabuliformes e esbatidos da Depressão Periférica, de atro surgem col inas emmeias laranjas discretas, que dão lugar a um terreno mais dissecado a leste, ao nos aproximarmos da "Serra da Fartura" (A AREU, 1972:93).

\section{Compart imentação hipsométrica}

O mapa de compartimentação hipsométrica (fig. 8) foi gerado no software Arc Map 9.1 fazendo uso do processo de triangulação.

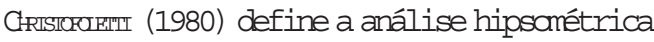
como o estudo das inter-relações existentes em determinada unidade horizontal de espaço no tocante à sua distribuição em relação às faixas altitudinais, indicando a proporção ocupada por determinada área da superfície terrestre em relação às variaçães altimétricas a partir de determinada isoípsa base.
Sendo assim, a compartimentação hipsométrica objetiva agrupar áreas em classes de altitudes similares para podermos diferenciar níveis de aplainamento e melhor analisarmos o papel da energia potencial do relevo. Além do que, neste caso, auxilia-nos a percebermos o contato entre os terrenos do cristalino - apresentanob cotas altimétricas mais elevadas (acima de 700 metros) - e os terrenos sedimentares, com cotas menores, bem como, as intrusões de cilabásio.

A produção do mapa hipsométrico (fig. 8) ccorreu a partir da digitalização das arvas altimétricas das quatro cartas topográficas que compõem a área da Bacia Hidrográfica do Rio Verde as quais, estão na escala 1:50.000 e apresentam eqüidistância das arvas de nível de 20 metros. As cotas altimétricas na Bacia Hidrográfica do Rio Verde variam de 560 metros no ponto ande este deságua no Rio Pardo na altura do município de Mbcoca (SP) (ponto de controle da bacia hidrográfica) e chega até 1300 metros em alguns picos da Serra da Mantiqueira (cristalino) .

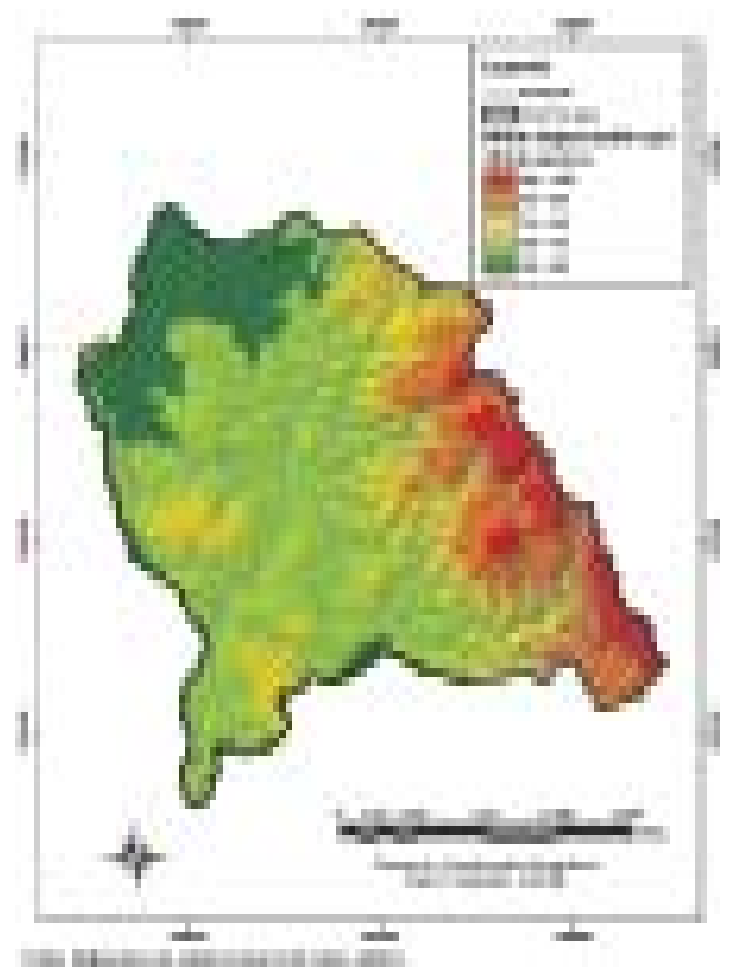

Fig. 8 - Mapa de Compartimentação Hipsométrica da Bacia Hidrográfica do Rio Verde (SP)

A figura 9 apresenta a porcentagem da área ocupada por cada classe de compartimentação hipsanétrica definida na Bacia Hidrográfica do Rio Verde. Sendo assim, evidencia-se um predomínio de cotas altimétricas entre 650 e 740 metros $(41,8 \%)$, ficando as cotas de 740 a 840 metros com 22, 3\% da área da bacia hidrográfica, as de 560 a 650 com 
15, 3\%, as de 840 a 960 metros representam 13, 9\% e as de 960 a 1300 metros chegam a 6,7\% da área total da bacia hidrográfica do Rio Verde.
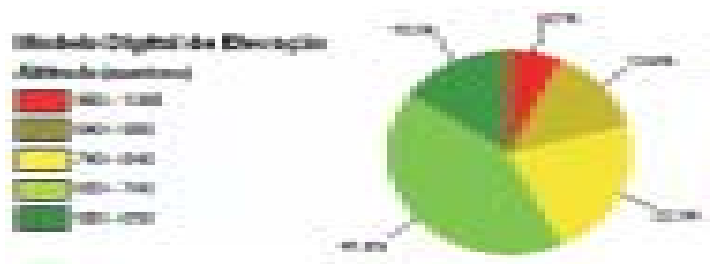

Fig. 9 - Compartimentação Hipsométrica- Bacia Hidrográfica do Rio Verde (SP) .

As cotas altimétricas entre 560 e 740 metros estão diretamente relacionadas com os terrenos sedimentares, ao passo que, as cotas acima de 740 metros de altitude caracterizam os terrenos do embasamento cristalino, bem como, as intrusões de diabásios em meio aos Depósitos Cenozóicos e sedimentos dos Grupos Tubarão e São Bento. Além disso, mais uma vez ressaltamos que na área da Serra da Mantiqueira observarmos a maior concentração de canais de primeira ordem, as quais, diretamente associados às maiores cotas altimétricas.

\section{Declividade}

O mapa de declividade (fig. 10) foi gerado no software Arc Mapo 9.1 a part ir do modelo digital do terreno da área da bacia hidrográfica do Rio Verde com o uso de interpolação por triangulação (função TIN) e foram definidas as classes das cotas altimétricas, bem como a análise das mesmas, segundo Ross (1994).

Adeclividade de um terreno tem interferência direta no volume e na velocidade das águas pluviais que escoam pelas vertentes (BerronI \& LavBard, 1990) . Sendb assim, o grau de decl ividade é fator fundamental na análise da dinâmica dos elementos que compõem a bacia hidrográfica e sua "fragi lidade".

Quanto ao relevo, a maior influência está no comprimento e na declividade das vertentes. As mais íngrimes facilitam a erosão dos solos na medida em que aumentam o escoamento superficial. Roose (1977, apoud TAMAS \& VI"IE, 1993) , cita trabalhas de diversos pesquisadores demonstrando que as perdas de terra crescem de modo exponencial em função do aumento da incl inação das vententes.

O mapa de classes de declividade (fig. 10) e a figura 11, no qual estão as valores ocupados pelas respectivas áreas de cada classe de declividade, revelam-nos que 44, 5\% da área da Bacia Hidrográfica do Rio Verde apresenta declividades em tomo de $0^{\circ}$ a $3,1^{\circ}, 37,1 \%$ da área apresentam de $3,2^{\circ}$ a $9,4^{\circ}$, $11,7 \%$ de $9,5^{\circ}$ a $18^{\circ}, 5,4 \%$ de $19^{\circ}$ a $35^{\circ}$ e $1,3 \%$ (incluindo as distorções no divisor da bacia hidrográfica) revelam declividades entre $36^{\circ}$ a $61^{\circ}$.

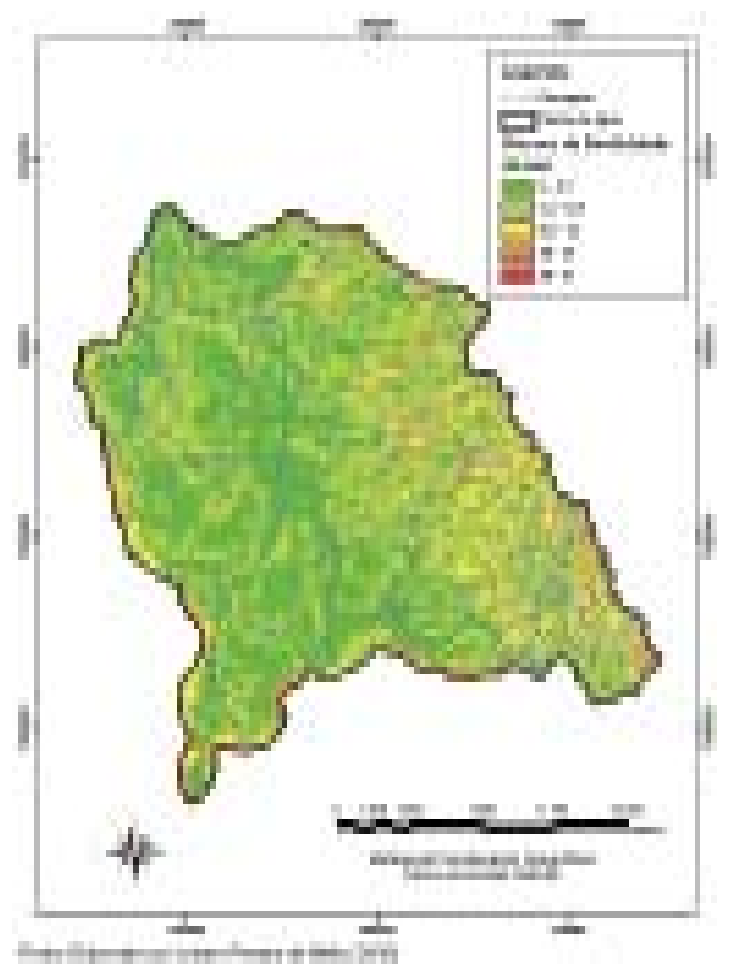

Fig. 10 - Carta Clinográfica da Bacia Hidrográfica do Rio Verde (SP) .

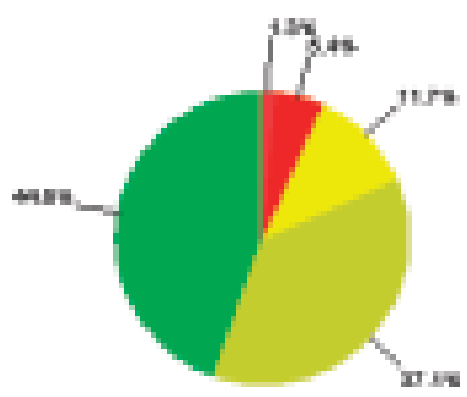

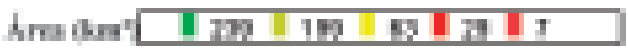

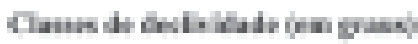

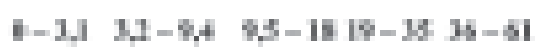

Fig. 11 - Áreas das classes de declividade - Bacia do Rio Verce (SP) .

Para Ross (1994) declividades de até 6\% caracterizam ambientes com baixa fragilidade (TAmera V) . A Bacia Hidrográfica do Rio Verde está classificado como de muito baixa a baixa fragi 7 idade nas áreas de até 3,1 (aproximadamente 6,9\% de declividade) , o que, como explicitado anteriormente, representa uma área de, aproximadamente, 239 km² (44, 5\% da área total da bacia hidrográfica) . 
As classes de baixa a média fragilidade ocupam una área de 199 km² (37,1\% do total) , pois, 3,20 a 9,4 equivalem de 6\% a 20\% de declividade. Sendo assim, os restantes $99 \mathrm{~km}^{2}$ (18,4\% da área total) com 9, $5^{\circ}$ a $61^{\circ}$ estão classificados dealta a mito alta fragi 7 idade, pois, equivalema valores acima de $20 \%$ de declividade.

Cbservandb os mapas da hierarquia fluvial (fig. 6) , de compartimentação hịpsanétrica (fig. 8) e a carta clinográfica (fig. 10, salvo as distorções da modelagem TIN) , ressaltamos que as maiores declividades estão concentradas nas áreas do embasamento cristalino da Serra da Mentiqueira, assim como, as maiores cotas altimétricas e o maior número de canais de primeira ordem, conseqüentemente, configurando uma região de maior susceptibilidade e/ou vulnerabilidade a processas morfogenéticos.

Além disso, ressaltamos que apesar das maiores declividades serem encontradas nas áreas do embasamento cristalino, os maiores comprimentos de vertente estão nas áreas das terrenos sedimentares (parte da Depressão Periférica) , sendo que, como comprovado por experimentos de campo realizados por Berron et al. (1972, apud BerranI \& LoMBARDI NEIO, 1990 :55) , quanto maior o comprimento das rampas (vertentes), maior a perda de solo por hectare.

\section{Solos}

A Bacia Hidrográfica do Rio Verde apresenta quatro unidades pedológicas, as quais estão nomeadas segundo o novo sistema Brasileiro de Classificação de Solos (EMBRAPA, 1999) e têm suas respectivas áreas de abrangência e porcentagens relativas expressas na TABHIA VI, bem como, suas distribuições espaciais conforme revela o esboço pedológico (fig. 11) elaborado a partir do Mapa Pedológico do Estado de São Paulo (Outverra et al, 1999 apud QAARIAROI et al. , 2006) .

TAma VI - Fragilidade dos tipos de solos

\begin{tabular}{|c|l|}
\hline $\begin{array}{c}\text { Classes de } \\
\text { Fragilidade }\end{array}$ & \multicolumn{1}{|c|}{ Tipos de Solos } \\
\hline Muito Baixa & $\begin{array}{l}\text { Latossolo Roxo, Latossolo Vermelho Escuro e Vermelho Amarelo } \\
\text { textura argilosa }\end{array}$ \\
\hline Baixa & Latossolo Vermelho-Amarelo textura média/argilosa \\
\hline Média & $\begin{array}{l}\text { Latossolo Vermelho-Amarelo, Latossolo Vermelho, } \\
\text { Argissolo Vermelho-Amarelo textura média/argilosa }\end{array}$ \\
\hline Alta & Argissolo Vermelho-Amarelo textura média/arenosa e Cambissolos \\
\hline Muito Alta & Argissolo Vermelho, Neossolo Litólico e Neossolo Arênico \\
\hline Fonte: Ross, 1994, adaptado à nova classificação de solos da Embrapa.
\end{tabular}

Enfatizamos aqui as possivveis problemas a serem encontrados no esboço pedblógico apresentadb (fig. 11) , os quais, ocorrem da ut i lização como referência, em função do tempo e objetivos do trabalho, do Mapa pedblógico do Estado de São Paulo na escala 1:500.000.
Segundo GuUtrRA \& BOteliHo (in Cunha \& GuerRA, 2001:184), os Latossolos, que no caso da Bacia Hidrográfica do Rio Vercde consti ituem uma área total (soma das áreas do Latossolo Bruno e Latossolo Vermelho) de 281,25 km² , ou seja, 53,52\% da área total da bacia hidrográfica e estão distribuŕdas, em sua maior parte (Latossolos Vermelhos), pelos terrenos da Depressão Periférica Paulista, caracterizam-se por apresentarem horizonte B latossólico (Bw) marcado por avançado estágio de intemperização; formação de argila de baixa atividade; capacidade de troca catiônica (CIC) baixa; cores vivas, neste caso, brunadas e avermelhadas; boa agregação; estnutura commente granular; e com pouca ou nenhuma acumulação de argila iluvial (translocada de horizonte superficial). São solos profundos, ácidas a fortemente ácidos (com exceção das eutróficas) , bastante porosas e permeáveis, de textura que varia de média a muito argilosa, e com predomínio de argilominerais do grupo 1:1 (caulinítico-gibsíticos), quartzo e autros minerais altamente resistentes à intemperização.

Sendo assim, os Latossolos, de um modo geral, apresentam reduzida susceptibil idade à erosão, pois a boa permeabilidade e drenabilidade e a baixa relação textural B/A (pouca diferenciação no teor de argi la do horizonte A para o B) garantem na maioria dos casos, uma boa resistência desses solos à erasão (GuERRA \& BOTELHO in CunHA \& GuerRA, 2001:184), conseqüentemente, confirmando este tipo de solo na classe de "fragilidade muito baixa" segundo a classificação de Ross (1994) contida na TAнma VI.

A Unidade "PVA 8", a qual, está distribuŕda na porção Leste/Sudeste da Bacia Hidrográfica do Rio Verde e ocupando uma área de 163, 1 km² $(31,04 \%$ da área total da bacia) dos terrenos pré-devonianos da Serra da Mantiqueira , compõe uma associação complexa de solos Litólicos, Cambissolos, Argissolos (Vermelho-Amarelo) e Petropl intossolos. É a unidade que apresenta os solos mais rasos e, por vezes, ocorrência de pedregasidade.

Os solos Litólicas ocorremnas áreas de topografia mais dissecada (contrafortes da Serra da Mentiqueira) , associados a afloramentos de rocha, de ummodo geral formam pequenas áreas mapeáveis em escalas de detalhe (maiores que 1:20.000); são solos pouco evoluídos, rasos (com, no máximo, 50 am até o contato com o substrato rochoso), caracterizam-se pela presença do Horizonte A sobre a rocha ou sobre o horizonte $C$ pouco espesso. Sendo que, devido à pequena espessura, GüRRA \& BотнHн (in CuNHA \& GtrRR, 2001:190-191) enfatizam que o fluxo d'água emseu interior éprecocemente interrampidb, facilitandb o escoamento em superfície, gerado pela rápida saturação do solo, e em sub-superfície, na zona de 
contato solo-rocha. Tal situação poole responder pela ocorrência de processos erosivos e, mais especificamente, de deslizamentos, agravando-se nas encostas mais íngrimes e desprovidas de vegetação.

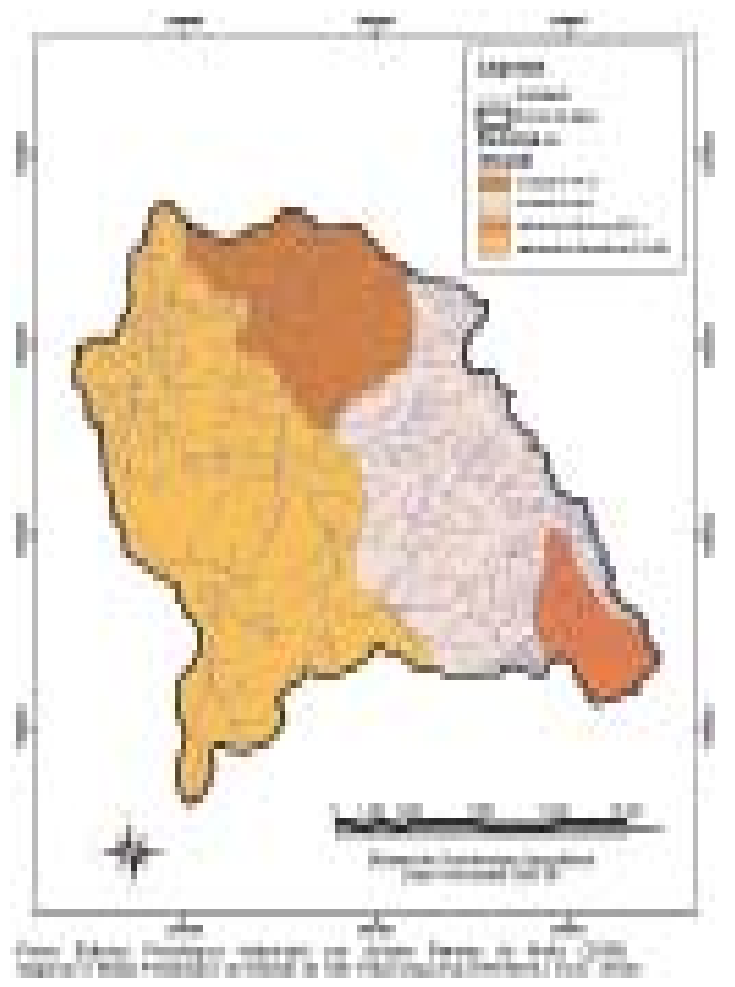

Fig. 11 - Esboço Pedológico da Bacia Hidrográfica do Rio Verde (SP) .

Os Cambissolos, segundo GuERRA \& BOIEHHO (in CUNHA \& GUERRA, 2001: 187) possuem horizonte B incipiente (Bi), caracterizadb pela presença de muitos minerais primários de fácil intemperização, ausência ou fraca presença de cerosidade, textura variandb de franco-arenosa amito argilosa, teor de silte, engeral, elevado e estrutura, commente emblocos, fraca ou moderada. O grau de susceptibilidade desses solos à erosão é variável, dependendo da sua profundidade (os mais rasas tendem a ser mais susceptíveis, devidb à presença da camada impermeável, representada pelo substrato rochaso), da decl ividade do terreno, do teor de silte e do gradiente textural, sendb que Ross (1994) as classifica, de modo geral (vide Thwa VI) camo de "alta fragilidadel".

TABera VI - Classes de Solo da Bacia Hidrográfica do Rio Verde

\begin{tabular}{|c|c|c|}
\hline Unidade Pedológica & $\begin{array}{c}\text { Area } \\
\mathbf{( k m}^{\mathbf{2}}\end{array}$ & $\begin{array}{c}\text { Porcentagem } \\
\mathbf{( \% )}\end{array}$ \\
\hline Latossolo Bruno (LB 1) & 31,2 & 5,92 \\
\hline Unidade PVA 11 & 81,15 & 15,44 \\
\hline Unidade PVA 8 & 163,1 & 31,04 \\
\hline Latossolo Vermelho (LV 49) & 250,05 & 47,60 \\
\hline Total & 525,5 & 100 \\
\hline
\end{tabular}

Fonte: Mapa Pedológico do Estado de São Paulo (apud QUARTAROLI et al., 2006)
Os Plintossolos são encontrados em ambientes específicos, onde há condições de escoamento lento ou encharcamento periódico. Sendo assim, áreas de relevo plano e suavemente ondulado, depressões, terraças e várzeas são os locais de maior incidência desses solos (GuERRA \& BOTHHO in CunHA \& GUERRA, $2001: 187)$. Os Plintossolos distinguem-se por passuir horizante plíntico, caracterizado pela presença de plintita em quantidade não inferior a 15\%, com espessura de no múnimo 15 am e profundidade variada, de acordo com o tipo de horizonte sobrejacente.

GuERRA \& BOTEUHO (in CUNHA \& GUERRA, 2001:188) ressaltam que no caso de aumento acentuado no teor de argi la dos horizontes superficiais para o horizonte plíntico ou da presença de petroplintita, formando uma camada coesa e contínua, principalmente se não estivermito profunda, intensifica-se a limitação das Plintossolos por susceptibi 7 idade à erosão, já que a permeabilidade toma-se extremamente prejudicada.

A Unidade "PVA 11" ocupa uma área de 81,15 km² (15,44\% da área total) que se estende na porção nordeste da Bacia hidrográfica do Rio Verde e, assim como a Unidade "PVA 8", também distribui-se sobre as terrenos pré-devonianos da Serra da Mantiqueira e é constituŕda de Argissolo Vermelho-Amarelo distrófico abrupto, A, moderado, textura arenosa/ média, ou arenosa/argilosa, ou média/argilosa ou média/média, álico.

Conforme GuERRA \& BOTELHO (in CUNHA \& GUERRA, 2001:184-185) as Argissolos caracterizam-se pelo horizonte B textural (Bt) , o qual é marcado por acumulação de argi la, por iluviação, translocação lateral intema ou formação no próprio horizonte. Em geral, apresentam diferenças significativas no teor de argila entre os horizontes Ae B (relação textural mais elevada do que a dos Latossolos) , passando de um horizonte superficial mais arenoso, para umhorizonte sub-superfcial mais argiloso. Tal fato pode representar um obstáculo à infil tração de água ao longo do perfil, diminuindo sua permeabilidade e favorecendb o esccamento superficial e sub-superficial na zona de contato entre as diferentes materiais.

Sendo assim, ainda conforme GuERR \& Bоाнін (in CtNA \& GHRRA, 2001:184-185), os Argissolos, apesar das suas características de agregação e boa estruturação (horizonte Bt em blocos angulares ou sub-angulares), apresentam certa susceptibilidade aos processas erosivos, que serão tão mais intensos quanto maiores forem as descontinuidades texturais estruturais ao longo do perfil. Conseqüentemente, segundo Ross (1994) (vide ThFarA VII), as Argissolos estão classificadbs em "fragilidade média" (Argissolo Vermelho-Amarelo textura média/argilosa), "fragilidade alta" (Argissolo Vermelho-Amarelo textura média/arenosa) e "fragilidade muito 
alta" (Argissolo Vermelho, o qual, não está contemplado na unidade PVA 11) .

Uso e ocupação da terra

O mapa de Uso e Ocupação da terra da Bacia Hidrográfica do Rio Verde (fig. 12) foi produzido a partir da compilação do trabalho de QUARTAROII et. al. (2006) - Mapa de Uso e cobertura das terras para o ano de 2003 (1:250.000) - o qual, foi obtido no site da Embrapa Monitoramento por Satélite em formato PDF, salvo em formato TIFF e inserido no software Arc Map 9.1, ande foi geo-referenciado e, posteriormente, digitalizadas todas as respectivas áreas de uso e ocupação da terra contidas na Bacia Hidrográfica do Rio Verde.

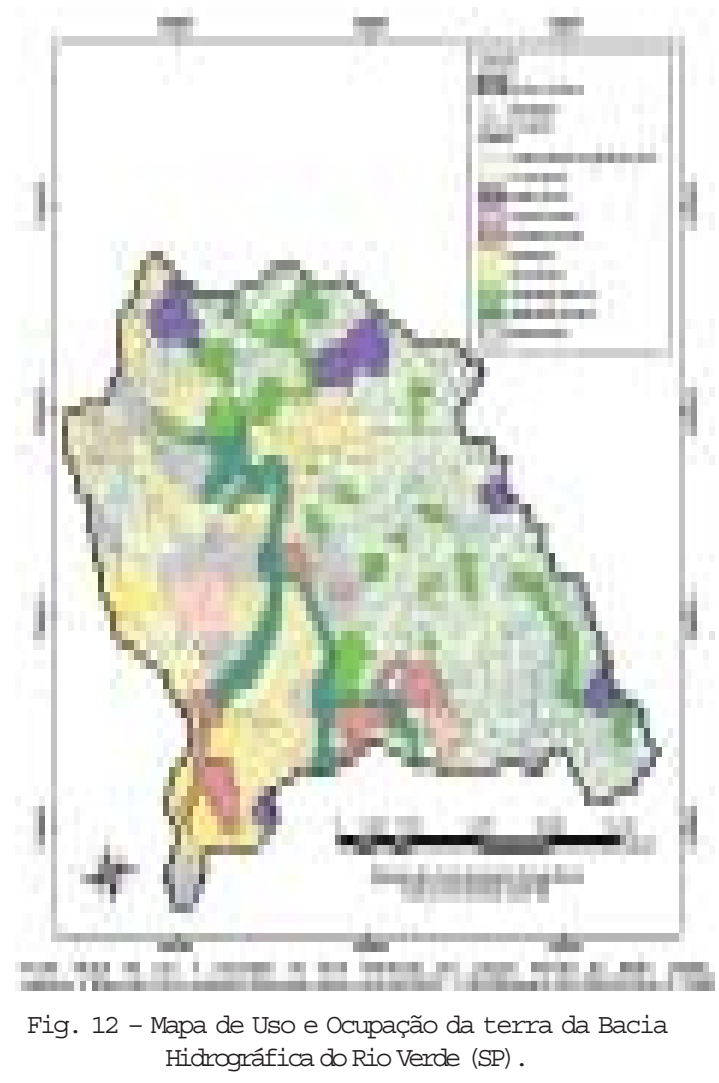

A Thस्A VIII revela que as pastagens apresentam a maior área ocupada $(40,15 \%)$ e, no caso da Bacia Hidrográfica do Rio Verde, as mesmas estão diretamente relacionadas às áreas da Serra da Mantiqueira em função do desmatamento que lá ocorreu para introdução do café que, atualmente, por conta das crises que enfrentou na década de 1930, teve suas áreas de plantio reduzidas.

Em seguida, temas as culturas amuais irrigadas por pivô relacionadas, principalmente, aos cultivos de batata e cebola nas áreas dos terrenos
Therefa VIII - Uso e ocupação da terra na Bacia Hidrográfica do Rio Verde (SP)

\begin{tabular}{|c|c|c|}
\hline Classes & Área $\left(\mathrm{km}^{2}\right)$ & Porcentagem(\%) \\
\hline Vegetação Natural & 53,1 & 10,10 \\
\hline Pastagem & 211,15 & 40,15 \\
\hline Lagoa & 0,7 & 0,13 \\
\hline Cafeicultura & 20,68 & 3,93 \\
\hline Área Urbana & 13,5 & 2,57 \\
\hline Silvicultura & 27,15 & 5,16 \\
\hline Culturas anuais & 24 & 4,56 \\
\hline Fruticultura & 24,5 & 4,66 \\
\hline Vegetação Ripária & 31,9 & 6,07 \\
\hline Culturas anuais irrigadas por pivô & 84,25 & 16,02 \\
\hline Canavicultura & 35,01 & 6,66 \\
\hline Total & 525,30 & 100 \\
\hline
\end{tabular}

sedimentares, com $84,25 \mathrm{~km}^{2}$ (16, 02\%) da área total, o que, constitui um importante elemento de análise na avaliação do estado de criticidade hídrica por que passa a Bacia Hidrográfica do Rio Verde (SP) .

A vegetação natural ocupa 53,1 km² $(10,10 \%)$, preferencialmente sendo preservadas nas áreas da Serra da Mantiqueira em função das maiores altitudes e declividades que ali ocorrem.

A canavicultura ocupa 35, $01 \mathrm{~km}^{2}(6,66 \%)$ e se difunde pelos terrenos sedimentares de menor declividade, ou seja, onde há condições de seu manejo mecanizado.

A vegetação ripária ocupa 31,9 km² $\quad(6,07 \%)$ ao longo, principalmente, dos canais de $3^{a}, 4^{a}$ e $5^{a}$ (canal principal) ordens.

Além do que, ressalta-se a quase que ausência de vegetação ripária, au mesmo, vegetação natural junto a maior parte dos canais de primeira ordem.

Por fim, a silviaultura oapa $27,15 \mathrm{~km}^{2} \quad(5,16 \%)$, a fnuticultura $24,5 \mathrm{~km}^{2}(4,66 \%)$, as culturas anuais (principalmente cebola, batata e arroz) ocupam 24 $\mathrm{km}^{2}$ (4,56\%) , a cafeicultura ocupa 20,68 km² $(3,93 \%)$ e as áreas urbanas representam 13,5 km² $(2,57 \%)$.

\section{Fragilidade ambiental da Bacia Hidrográfica do Rio Verde}

Ná análise aqui proposta, procuramos concatenar tanto os aspectos ligadbs às dinâmicas naturais e, por isso, ditos relacionados à vulnerabilidade e/ou susceptibilidade do meio, como as aspectos ligados às dinâmicas sócio-econânicas, au seja, confimmanob o conceito de "fragilidade ambiental" enquanto análise integrada do ambiente sob seus diferentes componentes: naturais e antrópicos.

O mapa síntese da fragilidade ambiental da Bacia Hidrográfica do Rio Verde (SP) foi construídb a partir da integração dos mapas temáticos de solo, 
hierarquia fluvial, uso e ocupação da terra, clinográfico e de compartimentação hipsométrica, os quais, foram trabalhados em ambiente SIG (ArC Møp 9.1) seguindo as processos abaixo representados:

10- As tabelas de atributos de cada mapa supracitado foram formatadas e seguindo os valores apresentados no Thmi IX, sendb assim, cada ID (identificador) (fig. 13) das respectivas classes mapeadas receberem um peso que variou de 1 a 4 conforme os dados contidas nas Th\#As IV, V, VI, VII e VIII que indicam, respectivamente, tipos de usos indicados para os diversos intervalos de classe de declive, fragilidade das classes de declive, fragilidade dos tipos de solos e graus de proteção das tipos de cobertura vegetal, além do que, da análise morfométrica e de sua implicação na determinação dos processos de morfogênese e pedogênese:

$2^{\circ}$ - Por meio da função Spatial Analyst os mapas temáticos (polígonos e linhas) foram convertidos em imagens TIFF conforme figura 13. As imagens foram geradas com tamanhos de pixel de $15.129 \mathrm{~m}^{2}$, assim, evitando a deformação das informações (pixels) e garantindo a relação de informaçães com o mínimo de distorção/generalização.

$3^{\circ}$ - Por fim, utilizamos a função Raster calarlator para construirmos o algoritmo de geração do mapa síntese da fragi lidade ambiental da Bacia Hidrográfica do Rio Verde (SP) .

Oalgoritmo utilizado (fig. 14) foi construídb da seguinte maneira:

Fragilidade $=\{\mathrm{Hf}+$ Hipso $+[3 \mathrm{xDec}]+[3 \mathrm{x}$ Uso $]+[2 \times$ Ped $]\} / 10$

Onde:

Hif - Hierarquia Fluvial;

Hipso - Compartimentação Hipsométrica;

DeC - Declividade;

Uso - Uso e ocupação da terra;

Ped - Solos.

TABRIA IX - Pesos segundo classes mapeadas para confecção do mapa síntese de fragilidade ambiental

\begin{tabular}{|c|c|c|}
\hline Mapa & Classes & Pesos - ID \\
\hline Clinográfico & Declividades & 3 \\
\hline Uso e ocupação da terra & Uso e ocupação & $\begin{array}{c}\text { Culturas anuais irrigadas por pivô-4; } \\
\text { Canavicultura }-4 ; \\
\text { Culturas anuais }-4 ; \\
\text { Área Urbana - 4; } \\
\text { Pastagens - 3; } \\
\text { Vegetação natural e ripária - } 1 \\
\text { Fruticultura - 3 } \\
\text { Silvicultura }-3 \\
\end{array}$ \\
\hline $\begin{array}{c}\text { Compartimentação } \\
\text { Hipsométrica }\end{array}$ & Cotas altimétricas & 1 \\
\hline \multirow[t]{2}{*}{ Hierarquia Fluvial } & \multirow[t]{2}{*}{ Ordens } & $1^{\mathrm{a}}$ ordem -2 \\
\hline & & De $2^{\mathrm{a}}$ à $5^{\mathrm{a}}$ ordem -1 \\
\hline \multirow[t]{2}{*}{ Esboço Pedológico } & \multirow[t]{2}{*}{ Solos } & Argissolos -2 \\
\hline & & Latossolos -1 \\
\hline
\end{tabular}

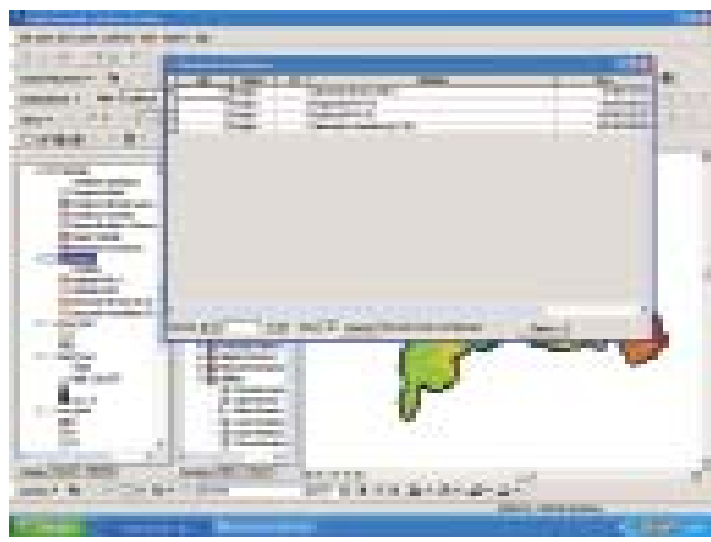

Fig. 13 - Formatação das tabelas de atributos dos mapas temáticos em ambiente SIG (Arc Mạp 9.1).

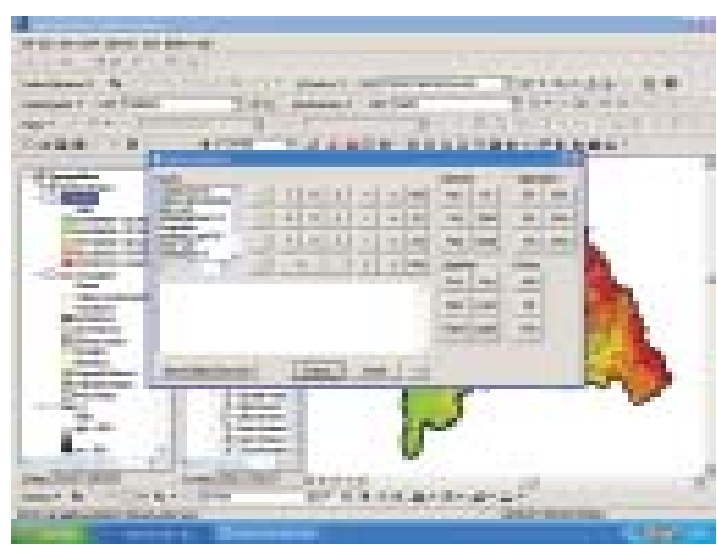

Fig. 14- Geração de algoritmo para cruzamento de dados e geração do mapa síntese (Arc Map 9.1) .

Os elementos explicitados no algoritmo acima foram escolhidos por estarem diretamente associados aos processos morfogenéticos, bem como, correspondendo aos conceitos de "fragilidade ambiental potencial" (elementos da dinâmica natural) e "fragilidade ambiental emergente" (elementos da dinâmica natural em interação com os elementos da dinâmica sócio-econômica) .

Como explicado anteriormente, na equação acima, foi dado peso "3" para os valores de declividade e de uso e ocupação da terra, peso "2" para os valores de solo e peso "1" para os valores da compartimentação hipsonétrica e hierarquia fluvial.

En seguida, as valores geradas para cada pixel da imagem do mapa de fragilidade ambiental (fig. 15) , conforme algoritmo supracitadb, foram divididas em 5 classes, a saber "muito baixa fragilidade"; "baixa fragilidade", "hécia fragilidade", "alta fragilidade" e "mitoalta fragilidade".

Os valores em área e porcentagem referentes às classes de fragilidade ambiental estão representados na TAвен IX e na figura 16, onde, observa-se que 221, 32 km² $(42,13 \%)$ da área da Bacia Hidrográfica 


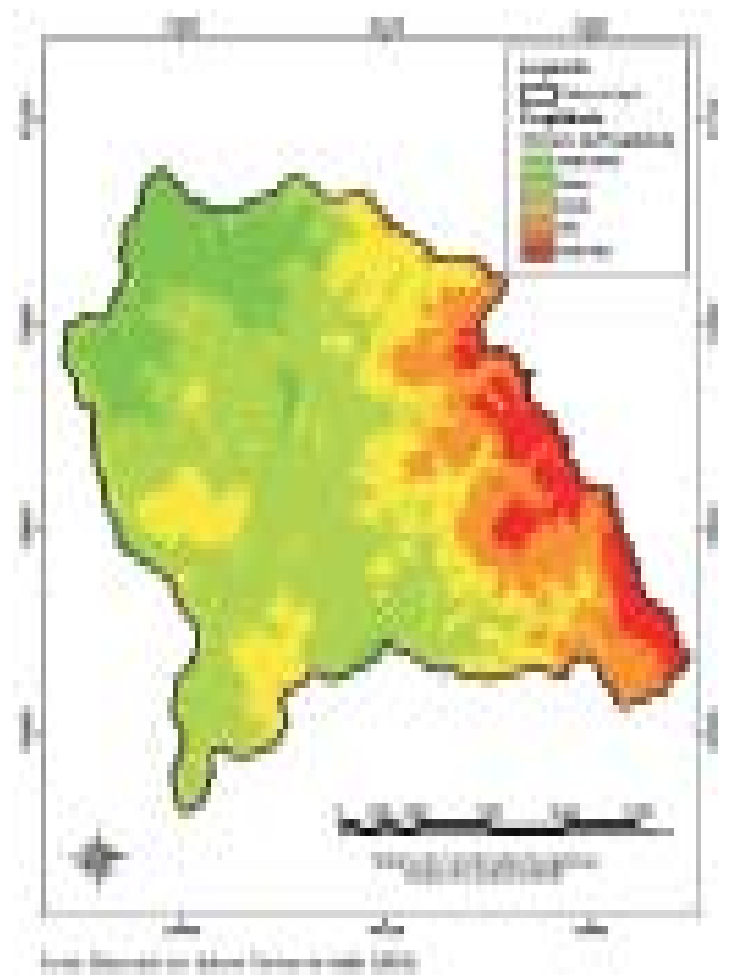

Fig. 15 - Mapa de Fragilidade Ambiental da Bacia Hidrográfica do Rio Verde (SP) .

Anoss des closes de Fraglidede Hnbiental ta

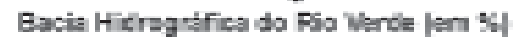
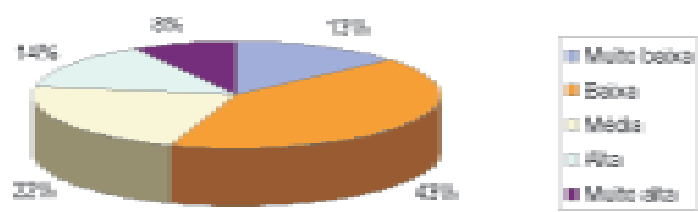

Fig. 16 - Áreas das Classes de Fragilidade Ambiental da Bacia Hidrográfica do Rio Verde (em \%)

do Rio Verde estão classificados como de "baixa fragilidade ambiental". Tais áreas estão localizadas sobre os terrenos sedimentares da Depressão Periférica caracterizadbs pelas baixas declividades, presença de Latossolos, menores cotas altimétricas e menor presença de canais de primeira ordem.

Temos que 116, 47 km² (22,17\%) estão classificadbs cono sendo de "média fragilidade ambiental" em função de serem áreas caracterizadas pela transição entre os terrenos sedimentares e os terrenos cristalinos e/Ounas intrusães de diabásios nos terrenos sedimentares, ande também se dá a presença de Argissolos. Além disso, também ocorre a presença de áreas urbanas e de alturas perenes inrigadas por pivô.

Uma área de, aproximadamente, $74,34 \mathrm{~km}^{2}$ $(14,15 \%)$ está classificada como sendo de "alta fragilidade ambiental", a qual, localiza-se na Serra da Mentiqueira.
Nas proximidades da região onde o Rio Verde deságua no Rio Pardo temos uma área de 69,5 km² classificada cono de "muito baixa fragilidade", pois, temos aí os menores valores altimétricos e de declividades, Latossolos e uma considerável área de vegetação natural preservada.

Por fim, temos nos topos da Serra da Mentiqueira $43,67 \mathrm{~km}^{2}(8,31 \%)$ classificados como sendo de 'muito alta fragilidade".

Sendo assim, percebemos que a partir dos parâmetros analisados o condicionamento das características morfométricas do relevo são preponderantes no que diz respeito aos processos morfogenéticos diretamente relacionados à vulnerabilidade ambiental e/ou fragilidade potencial, as quais, em conjunto com as formas de uso configuram os cinco níveis de fragilidade emergente apresentados na Tabela IX.

Para melhor analisarmos os dados da fragilidade ambiental na Bacia Hidrográfica do Rio Verde procedemos a generalização e/ou aglutinação das classes de fragilidade como apresentado na figura 17, na qual, unimos as classes de muito baixa à baixa fragilidade em uma categoria e as classes de média a muito alta fragilidade em atra categoria.

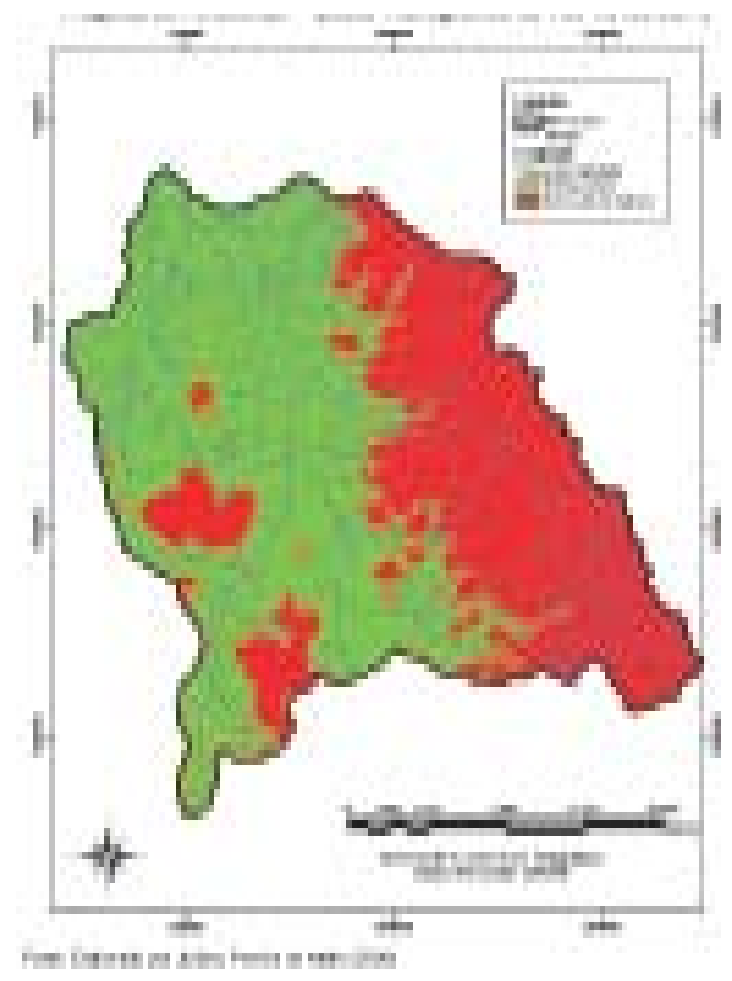

Fig. 17- Mapa de Generalização das Classes de Fragilidade Ambiental da Bacia Hidrográfica do Rio Verde (SP) .

Temos que, os 44,63\% da área representada pela categoria de média a muito alta fragilidade (representados emvermelho na figura 17) estão quase 
que totalmente relacionados à Serra da Mantiqueira, onde, a forte dissecação, o altogradiente altimétrico, o desmatamento em função da implantação dos pastos, a maior quantidade dos canais de primeira ordem e as declividades acentuadas intensificam os processos erosivos e, conseqüentemente, o assoreamento dos canais que levam à diminuição da vazão dos rios, a qual, também é prejudicada por represamentos particulares irregulares que causam forte impacto na hidrologia dos canais.

As áreas de média a muito alta fragilidade ambiental nos terrenos sedimentares da Depressão Periférica Paulista estão associadas a cotas altimétricas mais elevadas diretamente relacionadas às intrusões de diabásio (sills e diques) e usos agrícolas ligados a alturas anuis inrigadas por pivô, canavicultura e áreas unbanas - com destaque para a expansão do perímetro urbano do município de Casa Branca.

Sendo assim, a figura 17 ajuda-nos a distinguir melhor as áreas de maior susceptibilidade e fragi 7 idade ambientais segundo os processas naturais e sócio-econônicos que nelas ocorrem, as quais estão diretamente associados à situação de criticicidade hídrica da Bacia Hidrográfica do Rio Verde (SP) .

\section{Considerações finais}

Mesmo a metodologia desenvolvida nesse trabalho apresentando algumas limitações em termos das escalas das informações e mapas concatenados, buscamos contribuir para projetos e programas de planejamento ambiental, enquanto o pensar contínuo e integrado nas açães de intervenção (gestão) , mais especificamente abordando os usos da água dentro de uma cancepção sistêmica de bacia hidrográfica e de arranjo geográfico sob uma maneira capaz de sustentar as atividades humanas com um mínimo de distúnbios nos processos físicos, ecológicos, sociais e econâmicas.

O conceito de fragilidade ambiental procura relacionar homem e natureza sem direcionar a análise aos estudas sociais ou aos estudbs naturais, além do que, está ligado à susceptibili idade de algo sofrer intervençães, au de ser alteradb. Fintão, a fragi lidade do meio ambiente está ligada a fatores de desequilílorio, tanto de ordemnatural (alto grau de declividade, alto grau de erodibilidade, variações climáticas) quanto social (uso indevido do solo, intervenções em regimes fluviais, técnicas de altivo) .

Na Bacia Hidrográfica do Rio Verde a fragi lidade ambiental está fortemente relacionada às características naturais (solo, declividade, drenagem, altimetria e geologia) e histórico-sócio-econônicas da área da Serra da Mantiqueira, onde, a morfogênese sobrepõe-se à pedogênese e é potencializada pelas práticas de uso e ocupação das tenras.

Já com relação às áreas da Depressão Periférica Paulista há que se atentar para a diversidade dos tipos de uso e oapação agrícolas das terras enquanto potencializadores de processos de degradação ambiental em função das práticas de irrigação, manejo inadequado do solo e uso de agroquímicos emgeral.

\section{Referências bibliográficas}

ABREU, Adilson A. de (1972) - Estruturação de paisagens geográficas no médio vale do JaguaríMirim. Tese de datorado. Faculdade de Filosofia Letras e Ciências Humanas da USP, São Paulo.

At-Aravar, R.A.N., Foster, I.D.L., Bapan, S.M.J. (2003) - 'Groundwater vilnerabi lity and risk mapping for the Basaltic aquifer of the Azraqbasin of Jordan using GIS, Remote sensing and DRASIIC' . Applied Geography, 23, p. 303-324.

Broker, B. K. ; EstrR, C. A. G. (1997) - Detalhamento da metodologia para execução do zoneamento ecológico-econâmico pelos Estados da Amazônia. Legal. Brasília, MMASAE.

BerronI, J. ; Lonbardi Neio, F. ; Benatti JR, R. (1975) Equação de percós de solo. Instituto Agronâmico, Campinas, SP.

BertonI, J. \& LoMBARd Neio, F. (1985) - Conservação do Solo. Piracicaba, CERES.

Bertani \& LaMbardi Neio, F. (1990) - Conservação do Solo. 3 ed. São Paulo, Icone.

Bонஈ, Garrido M. \& SwIA, Antônio S. (2004) - "Bacia Hidrográfica e Qualidade Ambiental" . In VI"IE, Antônio Carlos \& GHसA, A. J. T. (organizadores) . Reflexões sobre a Geografia Fisica no Brasil. Rio de Janeiro, Ed. BertrandBrasil, p. $153-191$.

BRADY, N. C. (1989) - Natureza e propriedades dos solos. Trad. Antonio B. Neiva Figueiredo. $7^{a}$ ed. Rio de Janeiro, Freitas Bastos.

Cano, W. ; Brañão, Carlos A. ; Macter, Cláudio S. ; Macmo, Femando C. (2007) - Economia Paulista: dinâmica socícconômica entre 1980 e 2005. Campinas, SP, Editora Alínea.

CFrisiofoteilT, Antônio (1980) - Geomorfologia. São Parlo, Edgard Bluche.

Christofoletit, Antônio (1999) - Modelagem de Sistemas Ambientais. São Paulo, Edgard Blucher.

Canserro da bacia do Pardo (2003) - Plano de Bacia da Unidade de Gerenciamento de Rearrsas Hídricas do Rio Parob-URHI 4: Relatório Final. São Paulo. Constituição da República Federativa do Brasil (1988) . São Paulo, IMESP (Imprensa Oficial do Estado de São Paulo) . 


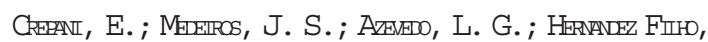
P. ; Florentano, T. G. ; Diarle, V. ; Barbosa, C. C. F. (1998) - Sensoriamento remoto e gegprocessamento aplicados ao zoneamento ecológico-econômico. Relatório INPE, São Jasé das Campos (SP) .

CinHA, Cenira M. L da. (1997) - Quantificação e mapeamento das perdas de solo por erosão com base na malha fundiária. Instituto de Geociências e Ciências Exatas. UNESP, Rio Claro.

ClNA, S. B. da, GthrRA, A. J. T. (1996) - "Degradação Ambiental". In GHera, Antônio T. \& Cinfa, Sandra B.da (organizadores). Geomorfologia e Meio Ambiente. Rio de Janeiro, Bertrand Brasil.

Deliberação CBH-PARDO 004/04. Declara crítica a Bacia Hidrográfica do Rio Verde. Ribeirão Preto, 25 de junho de 2004.

Dixan, B. (2005) - "Groundwater vulnerability mapping: A GIS and fuzzy rule based integrated tool". Applied Geography, 25, p.327-347.

FłiAs, D. (2003) - Globalização e Agriaultura: A região de Ribeirão Preto/SP. São Paulo, Editora da Universidade de São Paulo.

EMBRAPA. Centro Nacional de Pesquisa de Solos (1999) - Sistema brasi leiro de classificação de solos. Brasília, EMBRAPA.

FEEIMA (1991) - Vocabulário Básico de Meio Ambiente. $4^{a}$ ed. Rio de Janeiro, Petrobrás, Serviço de Comunicação Social.

Fratsorr, Camila (2005) - Valorização do Espaço e fragi 7 idade ambiental : o caso da construção do meio ambiente unbano da Bacia do Córrego Santo Antônio, Mogi Mirim (SP). Dissertação de Mestrado. Instituto de Geociências. Universidade Estadual de Campinas.

Gazeta de Vargem Grande do Sul (27/07/1994).

GHFRA, A. J. T. \& ВOHнH, R. G. M. (2001) - "Erosão dos Solos" . In Ctnha, S. B. da \& GHRRA, A. J. T. (organizadores), Ceamorfologia do Brasi 7. $2^{a}$ ed. Rio de Janeiro, BertrandBrasil.

GAaser, G. (1983) - "Unstable and vulnerable ecosystems: A comment based an mab research in island ecosystems" . Mountain Research and Develqument, Vol. 3, n 2, p.121-123.

Longman Dictionary of Geography: Human and Physical. Longman House, UK, 1985.

Meiso, Juliano Pereira de (2003) - Utilização de técnicas morfométricas no estudo de voçorocamento: O caso da voçoroca da Bacia do Ribeirão Santo Antônio, Município de Mogi Mirim (SP) . Mbnografia. Campinas (SP), Instituto de Geociências, UNICAMP.

Menck, João Carlos (2001) - "A inserção da variável ambiental nos usos dos recursos hídricos" . A gestão das águas, Ano 1, no 2, julho/2001. Associação Brasi leira da Batata.
Mendonç, Izaque Francisco Candeia de (2005) Adequação do uso agrícola e estimativa da degradação ambiental das terras da microbacia hidrográfica do riacho Una, Sapé-PB. Tese de Doutorado, Faculdade de Engenharia Agrícola. Universidade Estadual decampinas, SP.

MhieIro, C. A. F. (2001) - Geossistemas: a história de uma procura. São Paulo, Contexto.

Naver, Z. (1994) - Landscape Ecology: Theory and Application. Springer-Verlag, New Yodk.

Newsor, M. (1997) - Land, Water and development: sustainable management of river basin systems. New York, Routledge.

Nirsan, C. \& GRerson G. (1995) - "The Fragility of ecosystems: a revew" . Jamal of Apolied Ecology, 32, p 677-692.

Nucci, J. C. \& CAvarHeriRo, F. (1997) - "Adensamento Urbano e Qualidade Ambiental" . VII Simpósio Brasileiro de Ceografia Física, D-ROOM, Aritiba.

Nĩ̃es, J.E.V. ; Sorrinto, N. M. B. Amaral; Patmirrt, F. ; Mesquita, A. A. (1999) - "Conseqüências de diferentes sistemas de preparo do solo sobre a contaminação do solo, sedimentos e água por metais pesados". Revista Brasi leira de Ciência do Solo, 23, 981-990.

Pewirf, L. Charlet (2002) - ApticăoAgrícola das terras e sensibi 7 icade ambiental: proposta metooblógica. Tese de Doutorado. Faculdade de Engenharia Agrícola. Universidade Estadual de Campinas (SP) .

Profilo SAPUCÁ́. (1979) - Estados de São Paulo, Rio de Janeiro e Minas Gerais: Relatório final de Geologia. DNPM/CPRM, Superintendência Regional de São Paulo.

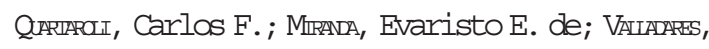
Gustavo S. ; Horr, Marcos C. ; Ckrscuoo, Cristina; GuinarẽEs, Marcelo (2006) - Uso e Cobertura das Terras na Região Nordeste do Estado de São Paulo. Campinas: Enbrapa Mbnitoramento por Satélite.

RanaHo, J. F. G. P. ; Sorrino, N. M. B. Amaral; Vhtoso, A. C. X. (1999) - "Aámulo de metais pesadas em solos altivadbs com cana-de-açúcar pelo uso contínu de adubação fosfatada e água de irrigação" . Revista Brasileira de Ciência db Solo, 23, 971-979.

Ross, Jurandyr L.S. (1990) - Geomorfologia: Ambiente e Planejamento. São Paulo, Contexto (Série Repensando a Geografia) .

Ross, Jurandyr L. S (1994) - "Análise Empírica da Fragilidade dos Ambientes Naturais e Antropizados" . Revista do Departamento de Geografia, São Paulo, no 8, p.63-74.

Ross, Jurandyr L. S. (1996) - "Geomorfologia Aplicada aos ETAS e RTMAS" . In: GHRRA, Antonio T. \& CunHA, Sandra B.da (organizadores), Geomorfologia e Meio Ambiente. Rio de Janeiro, BertrandBrasil, p. 291-336. 
Ross, J. L. S. \&Del Prette, Marcos E. (1988) - 'Rearrsos Hídricas e as Bacias Hidrográficas: Âncoras do Planejamento e Gestão Ambiental" . Revista do Departamento de Geografia, n. 12, USP, p.88-121.

Sanios, I. (1997) - Proposta de Mapeamento da Fragi lidade Ambiental na Bacia Hidrográfica do Rio Palmital, Região Metropolitana de Aritiba. Mbnografia de conclusão de curso de Geografia. Universidade Federal do Paraná.

Santos, I. dos \& Vir'E, A C. (1998) - "Proposta de Mapeamento da Fragilidade Ambiental na Bacia Hidrográfica do Rio Palmital, Região Metropolitana de Aritiba" . I Forum de Geo-BioHictrologia, Aritiba, Anais, p.123-135.

SIGRH (1999) - Diagnástico da Bacia Hidrográfica do Rio Parob: "Relatório Zero".

S匹VA, João dos Santos Vila da (2003) - Análise multivariada em zoneamento para planejamento ambiental; estudb de caso: bacia hidrográfica do alto rio Taquari MS/MT. Tese de Doutorado, Faculdade de Engenharia Agrícola. Universidade Estadual de Campinas.

Sorchalla, V.B. (1977) - "O Estudo de Geossistemas" . Revista IGUUSP, Sérienétoobs em Questão, SP, n 16.

Saza, George Taylor; BRtcauI, Luiza Leonardi; Mbसio, Mercelo Almeida; LiNA, Silma; CArenE, Sueli (2002) - "Água: Geopolítica Intemacional e Propostas para um Estudb Integrado de Bacias Hidrográficas" . Geografares, Vitória, n’ 3, p.69-77.

SPliminov, A. I. (1981) - Principios de la Metooblogía de las Investigaciones de Campo y el Mapeo Geomorfológico. Habana, Universidad de la Habana, Facultad de Geografía.

Seër, C. \& Ross, J.L.S. (2004) - "Análise comparativa da fragilidade ambiental com aplicação de três modelos" . Geousp - Espaço e Tempo, São Paulo, n०15, p.39-49.
TAMPAS, A. C. , VIIIE, A. C. (1993) - "Erosão das solos e assoreamento de represas: o caso de Monte Aprasivel (SP)". Geografia, 18 (1) , p.51-95.

Thavas, D.S.G. \& Aurisan, R. J. (1993) - Landscape Sensitivity. Chichester. JohnWiley \& Sons.

TRrcarr, J. (1977) - Ecootinâmica. Rio de Janeiro, IBGE/ SUPREN.

VIr"E, A. C. (1997) - "Metodologia para Calculo de Perdas de Solo em Bacias de Drenagem" . Bol. Par. de Geociências, n 45.Ed. da UFPR, p. 59-65.

VitTe, A C. \& Santos, I. dos (1999) - "Proposta Metodológica para Determinação de Unidades de Conservação a partir do Conceito de Fragilidade Ambiental". Revista Paranaense de Geografia, n 4, p. 60-69.

Sites consultadbs:

EMBrapa Monttoramento por SATÉltte. Disponível em: www. cnpm. embrapa.br - Consultado em 07 de janeiro de 2008.

FunDAÇÃo SEADE - Informações demográficas. Disponível em: uww. seade.gov.br. Consultado em 7 de jutho de 2005.

IBGE - Informações demográficas. Disponível em: www. ibge.gov.br. Consultado em 8 de jultho de 2005.

GNP/TAC - Parceria Global para Água. Disponível em <http: //www. genderandwateralliance. org/ portuguese/fags.asp>. Consultado em 3 de abril de 2005.

TORNATORE, Nicola (2004) . "Rio da bacia do Pardo pode desaparecer" . Consema. Disponível em: $<$ <ww.uniagua.org.br>. Consultado em 03 de abril de 2005. 